\title{
Design and Rating of Risk-Contingent Credit for Balancing Business and Financial Risks for Kenyan Farmers
}

\author{
Apurba Shee (University of Greenwich), Calum G. Turvey (Cornell University) and Liangzhi \\ You (IFPRI)
}

\begin{abstract}
Weather related agricultural risks and limited access to credit are serious impediments to agricultural productivity and growth in developing countries. This paper describes a novel insurance linked credit model piloted in Kenya, where insurance markets are effectively absent, and farmers do not borrow because of the risk of losing their collateral. One of the challenges in deigning bundled credit products, in the absence of traded securities, is the actuarial pricing and risk rating of the insurance and the loan product. We develop a rainfall linked risk-contingent credit that transfers drought risk related perils from borrower to lender via insurance mechanism that provide a balance between business and credit risks for smallholder farmers. We describe the methodology used to design and rating of a risk-contingent structured operating agricultural credit instrument using CHIRPS rainfall data from 1981-2016 in Kenya. We illustrate the use of Monte Carlo methods to risk modelling that can be integrated within general insurance and credit rating framework. The innovative design and methodology presented in this paper are as important as the product delivery mechanism and will be of interest to specialists in development economics and agricultural finance.
\end{abstract}

Keywords: Kenya, bundled credit, risk rationing, agricultural weather risk, risk modeling JEL Code: Q140

\section{Contact Author:}

Apurba Shee

Business Development Economist, Natural Resources Institute, University of Greenwich, UK a.shee@gre.ac.uk

Apurba Shee is Business Development Economist, Natural Resources Institute, University of Greenwich, UK, Calum G. Turvey is W.I. Myers Professor of Agricultural Finance, Charles H. Dyson School of Applied Economics and Management, Cornell University USA, and Liangzhi You is a Senior Research Fellow, International Food Policy Research Institute, Washington DC, USA.

This research was funded through Global Resilience Partnership by Rockefeller Foundation and US Agency for International Development (USAID) and Agricultural Insurance Thematic Window of the International Initiative for Impact Evaluation (3ie). We appreciate generous hospitality provided by our project partner Equity Bank Kenya Ltd. The opinions expressed in this paper do not necessarily reflect the views of our donors or partners. Any errors that remain are the authors' responsibility. We would like to thank the anonymous reviewer for useful comments that improved the paper. 


\section{Introduction}

Uninsured risks are a major cause of low agricultural productivity in Sub-Saharan Africa. The main uncertainty in Kenya's agricultural economy is drought and other adverse weather conditions that severely affect agricultural livelihoods. With $80 \%$ of the population employed in agriculture and $22 \%$ of the country's overall GDP derived from agriculture, enhancing agricultural productivity is critical for Kenya. According to Government of Kenya, four consecutive years (2008-2011) of drought amounted to US \$12.1 billion in losses, including losses in assets and from disruptions in the economy flow across all sectors. Such severe shocks cannot be financed by the government and donor community alone. Moreover, lack of capital and perceived risks limit farmers' ability to purchase agricultural inputs and access credit, contributing to low agricultural productivity. Lenders in Kenyan credit market limit the supply of credit to borrowers because of seemingly uninsurable weather risks tied to the possible failure of seasonal rainfall. In few markets where farmers do receive credit, loans are made under relatively high collateral restrictions which farmers are reluctant to risk (risk-rationing). Consequently, borrowers voluntarily withdraw from the credit market which in turn suppresses incentives for lenders to expand financial services (quantity rationing). Ultimately, the lack of credit access forces farmers to adopt low-risk low-return activities, and this is considered a main driver of persistent poverty (Barrett et al. 2006; Santos and Barrett 2006). In a base-line survey tied to the randomized control trial (RCT) implementation of risk-contingent credit product discussed in this paper, we found that only $10.3 \%$ of farmers were quantity rationed (applied for credit but did not receive any or full amount) while the risk rationed were $38.4 \%$. The degree of risk rationing is consistent with prior work by Boucher et al. (2009) and Verteramo-Chiu et al. (2014) and is 
also consistent with recent studies in microfinance which showed limited demand for microcredit at the market rate (Johnston and Morduch 2008; Banerjee et al. 2015).

Since credit rationing and risk rationing are largely a consequence of uninsured weather risk there is a need to financial engineer credit products to balance, business, financial and credit risks facing both borrowers and lenders to make credit markets work in Kenya. Some marketbased innovative risk management solutions are necessary to manage agricultural weather risks and to provide access to credit to the farmers. To address this problem, we developed - and present in this paper - a linked financial product in the form of Risk-Contingent Credit (RCC). $\mathrm{RCC}$ in this instance takes the form of a short-term loan with a payoff structure that is linked to shortfalls in cumulative seasonal rainfall (in $\mathrm{mm}$ ) below a target. When triggered, the insurance part offsets the loan repayment obligations of farmers, which in turn removes, or at least reduces, the credit exposure of lenders. In our model the underlying risk is captured through satellitederived rainfall data validated with weather station data based on state-of-the-art remote sensors. In providing a financial tool that transfers drought risk-related perils facing borrowers and lenders via insurance and reinsurance markets, risk-rationing and credit rationing can be reduced, increasing, in turn, the elasticity of credit demand and supply.

Because the insurance component of RCC substitutes for collateral, it is more financially inclusive than conventional credit products where a collateral is usually needed. Thus, RCC can bring risk-rationed farmers (who tend not to borrow or borrow less than optimal for fear of losing collateral and falling into a credit-driven poverty trap) into the credit market. In RCC the indemnity from the insurance is applied to the underlying debt obligation or debt service, thereby reducing the probability of default on loans by producers, improving risk bearing ability and trust which can encourage high uptake of RCC. It also eliminates the drawbacks of standalone index 
insurance products by not requiring the farmers to pay premium upfront and out of pocket. RCC avoids the stringent collateral requirement by linking repayments to underlying risk. RCC thus offers a market-based solution that would provide larger and long-term credit to cater to the investment need for agriculture in Kenya.

One of the challenges in designing bundled credit products, in the absence of traded securities, is the actuarial pricing and risk rating of the insurance and the loan product. Since few attempts have been made on delivering RCC to farm households, it is important for agricultural economists, insurance specialists, finance specialists and integrators to understand the financial engineering employed in the design and rating of bundled insurance. In this paper we present the details of our rating methodology as actually employed in the field with banking and insurance partners. It is our belief that the innovative designs and methods are as important as the product delivery mechanism itself, and with rising interest in bundled credit products like RCC this paper will be of interest to specialists in development economics, agricultural finance, development finance, agricultural insurance and agricultural micro insurance. The paper is structured as follows. Section 2 develops the risk-contingent credit model. Section 3 describes the geographic region and summarizes the data on which the model is based. Section 4 presents the empirical structure and rate making of RCC. Section 5 provides concluding comments and implementation challenges.

\section{Risk-contingent credit model}

Unlike traditional credit products, RCC structure facilitates risk management by layering hedging protection into loan payment obligations. An emerging literature on RCC includes Giné and Yang (2009), Carter (2011), Karlan et al. (2011), Miranda and Gonzalez-Vega (2011), 
Collier et al. (2011), Shee and Turvey (2012), Shee et al. (2015) and Casaburi and Willis (2015). As early as Bester (1985) it was shown that there could be a tradeoff between higher interest rate and lower collateral and that no credit rationing would occur if lenders offered different interest rates and collateral requirements. However, this did not give credence to incomplete markets nor the presence of significant covariate risks that could affect multiple borrowers simultaneously, nor widespread risk-rationing amongst a borrower group unwilling to risk consumptive and productive assets against credit default. Risk contingent credit resolves this problem by essentially substituting the Bester premium for insurance and transferring the regularization costs of collecting and disposing of collateral by the lender. With RCC, the payout from the insurance is applied directly to the underlying debt obligation or debt service, thereby reducing the probability of default on loans by producers, improving risk bearing ability, enhancing the supply of credit, and facilitating investment and development.

Below we provide a brief description of RCC and how it can protect farmers from drought related production risk. In Figure 1 the upper graph shows loan repayment and the lower graph illustrates the underlying insurance payout in relation to worsening conditions (to the left). If the underlying risk (weather-related) worsens and crosses a certain threshold, or trigger, the total repayment obligation of a farmer falls linearly with the difference deposited directly into the borrowers' loan account at the bank by the insurer. On the other hand, if the underlying risk is not triggered the loan has to be repaid at the risk-contingent interest rate (which will be higher than the market base rate). RCC is designed with an actuarially fair interest rate that is interlinked with the underlying weather risk. 


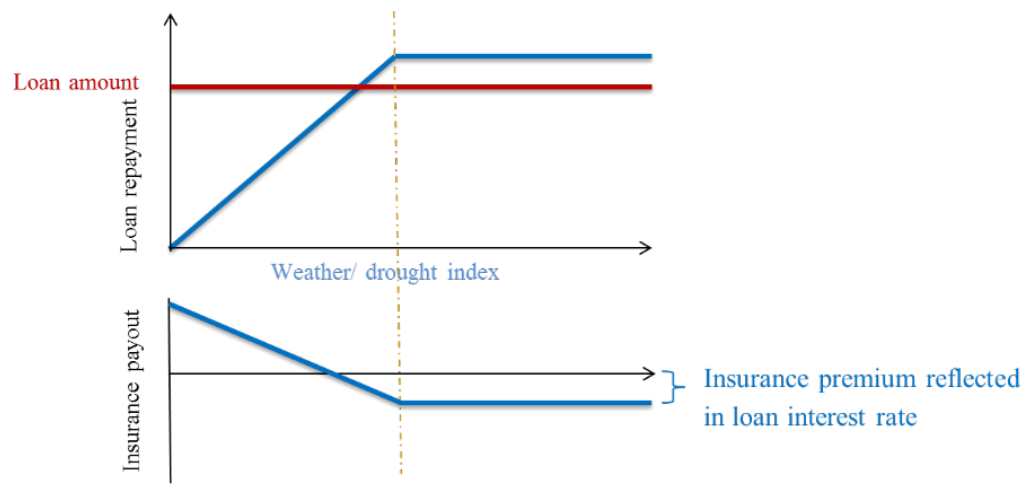

Figure 1 Illustration of Risk-Contingent Credit (RCC) mechanism

Most of the Kenyan medium and small farmers we met require operating loans for a crop year (around 8 months to 1 year) starting in September before the beginning of the long rains and ending in May, shortly after the end of short rains. Farmers take money for the investment on the crop production and generally repay the loan amount by selling their produce after the harvest. Whether long rains, and/or short rains fail directly affects their repayment ability to the banks. Facing these weather risks the proposed RCC is designed with a cumulative, dual trigger, weather insurance based on the lower-partial moments of the rainfall probability distribution below a specified rainfall coverage level. This coverage level is determined by the rainfall measured at the $15^{\text {th }}$ percentile, which in probability amounts to a payout in about 15 of 100 years. The essence of the RCC design is to insure the loan against adverse rainfall movements by directly imbedding onto the operating loan contract weather insurance.

Losses can come from both the long rains and the short rains. We define the seasonal rainfalls as $R_{L}\left(t_{L}, T_{L}\right)$ for long rains starting around October 15 and ending around January 15, and $R_{S}\left(t_{S}, T_{S}\right)$ for short rains starting around March 15 and ending around May 15 where $t$ is specific decadal in year $T$. Since the rainfall distributions differ by season and region, we treat each 
differently and define $g_{i}\left(R_{i}\left(t_{i}, T_{i}\right)\right), i=L, S$ as separate probability distributions for long and short rains.

A particular problem is in defining the loss. To capture this, we examine the historical probabilities and determine a particular rainfall coverage (or trigger or strike) below which a loss arises. This we do for both seasons. The loss is measured by $\operatorname{Max}\left(0, Z_{i}-R_{i}\left(t_{i}, T_{i}\right)\right)$ to capture the rainfall deviation below the trigger level, $Z_{i}$. We set this trigger level equal to that rainfall measure recorded at the $15^{\text {th }}$ percentile ${ }^{1}$. If actual rainfall is below the trigger, then the rain shortfall is $\left.Z_{i}-R_{i}\left(t_{i}, T_{i}\right)\right)$. Otherwise if $Z_{i} \leq R_{i}\left(t_{i}, T_{i}\right)$ rainfall is deemed sufficient to harvest a crop and repay the loan. Across all possible rainfall outcomes defined by the probability distribution function $g_{i}\left(R_{i}\left(t_{i}, T_{i}\right)\right)$ the mean deviation below the trigger is defined by

$$
E\left[\operatorname{Max}\left(0, Z_{i}-R_{i}\left(t_{i}, T_{i}\right)\right)\right]=\int_{\operatorname{Min}\left(R_{i}\left(t_{i}, T_{i}\right)\right)}^{Z_{i}}\left(Z_{i}-R_{i}\left(t_{i}, T_{i}\right)\right) g_{i}\left(R_{i}\left(t_{i}, T_{i}\right)\right) d R_{i}
$$

To capture the economic loan loss, we define a 'tick' by

$$
\psi_{i}=\frac{f}{Z_{i}-\operatorname{Min}\left(R_{i}\left(t_{i}, T_{i}\right)\right)} .
$$

Here, $f$ is the loan principal (e.g. 10,000 shillings) and $\operatorname{Min}\left(R_{i}\left(t_{i}, T_{i}\right)\right)$ is the minimum recorded rainfall recorded in our data series. The tick value is defined so that an amount $\psi_{i}$ is paid on every mm of rainfall below $Z_{i}$. If actual rainfall breaches the minimum rainfall then the loan indemnity equals $f$ exactly; in other words, in the worst-case scenario the farmer pays only the interest on the loan.

\footnotetext{
${ }^{1}$ Setting the trigger or strike level requires trade-off between coverage level and cost of insurance. We followed Chantarat et al. (2013) and depicted the time series of cumulative sub-county level rainfall for last 35 year and compared severe drought events reported by the communities and found that the rainfall levels at 15 percentile for all short and long rain failures were able to trigger the reported drought events. Higher triggers of course can capture any short and long rain failures but risk premium would become excessively high for farmers' risk bearing ability.
} 
Under these assumptions, we define the present value of loan repayment as

$$
B=e^{-i T}\left(f e^{i^{*} T}-\left(\psi_{L}\left[\operatorname{Max}\left(0, Z_{L}-R_{L}\left(t_{L}, T_{L}\right)\right)\right]+\psi_{S}\left[\operatorname{Max}\left(0, Z_{S}-R_{S}\left(t_{s}, T_{s}\right)\right)\right]\right)\right),
$$

where $i^{*}$ is the standard interest rate on operating loans (e.g. 12\%). The amount of loan including interest that would ordinarily be repaid at the end of the loan period is $f e^{i^{*} T}$. This loan repayment is discounted at the bank's cost of capital, $i$. Across all possible long and short rain outcomes the expected loan repayment is given by

$$
E[B]=e^{-i T}\left(f e^{i^{*} T}-\left(\psi_{L} E\left[\operatorname{Max}\left(0, Z_{L}-R_{L}\left(t_{L}, T_{L}\right)\right)\right]+\psi_{S} E\left[\operatorname{Max}\left(0, Z_{S}-R_{S}\left(t_{s}, T_{s}\right)\right)\right]\right)\right)
$$

In practice we have found that, while low, the correlation between rainfall in the long and short rains is positive. We therefore draw from joint or correlated probability distribution functions so that across all possible rainfall outcomes in both the long and short rains the expected loan losses to the lender is given by

(5) $\quad v=\int_{M i n\left(R_{L}\left(t_{i}, T_{i}\right)\right)}^{Z_{L}} \int_{\operatorname{Min}\left(R_{S}\left(t_{i}, T_{i}\right)\right)}^{Z_{S}}\left(\psi_{L}\left(Z_{L}-R_{L}\left(t_{L}, T_{L}\right)\right)+\psi_{S}\left(Z_{S}-R_{S}\left(t_{s}, T_{s}\right)\right)\right) g\left(R_{L}, R_{S}\right) d R_{L} d R_{S}$

The value, $v$, is also equal to the actuarial value of the losses.

The present value of such an operating loan for a borrowed amount $f$ and embedded rainfall insurance can be written as,

$$
E[B]=e^{-i T}\left(f e^{i^{*} T}-v\right)
$$

In the absence of rainfall risk the present value of the loan without the imbedded insurance is,

$$
B_{1}=e^{-i T} f e^{\left(i^{* *}\right) T}
$$

Therefore, to hedge the weather risk with the embedded rainfall insurance, the interest rate charged by the lender $\left(i^{*}\right)$ can be calculated by equating (6) and (7); 


$$
e^{-i T}\left(f e^{i^{*} T}-v\right)=e^{-i T} f e^{\left(i^{* *}\right) T}
$$

and solving for $i^{*}$;

$$
i^{*}=\frac{\ln \left[\frac{v}{f}+e^{\left(i^{* *}\right) T}\right]}{T},
$$

or

$$
i^{*}=\frac{\ln \left[\frac{E\left[\psi_{L}\left(Z_{L}-R_{L}\left(t_{L}, T_{L}\right)\right)+\psi_{S}\left(Z_{S}-R_{S}\left(t_{s}, T_{s}\right)\right)\right]}{f}+e^{\left(i^{* * *}\right) T}\right]}{T}
$$

Equation (10) provides the exact formula for calculating the interest rate on an operating loan with payment protection against drought conditions arising from shortfalls in long and/or short rains.

\section{Geographic region, risk rationing and rainfall data}

Machakos County is a semi-arid and hilly terrain area in Eastern province of Kenya. It receives very low annual rainfall of around $700 \mathrm{~mm}$ per year with average rainfall in long and short rain seasons being 315 and $266 \mathrm{~mm}$, respectively (GOK 2014). Due to this semi-arid climate agriculture is practiced smallholder farmers with maize being the main food crop. The RCC pilot area covers eleven divisions in the Machakos County including Central Machakos, Yathui, Yatta, Masinga, Matungulu, Kalama, Kathiani, Mwala, Kangundo, Ndithini, and Mavoko. Maize is the dominant crop in the area with some intercropping with perennial fruits or other cash crops. Most farms in this area are smallholder farms, with limited resources, and little to no access to credit. It is universally acknowledged by farmers that the primary risk faced are failures in the long and/or short rains. While rainfall is variable in the long and short rain periods 
(October $15^{\text {th }}-$ January $15^{\text {th }}$, and March $15^{\text {th }}$-May $15^{\text {th }}$ ) the infrequent failure of one or the other, and sometimes both rainfalls causes great hardship, and almost certain default on loans if credit were provided.

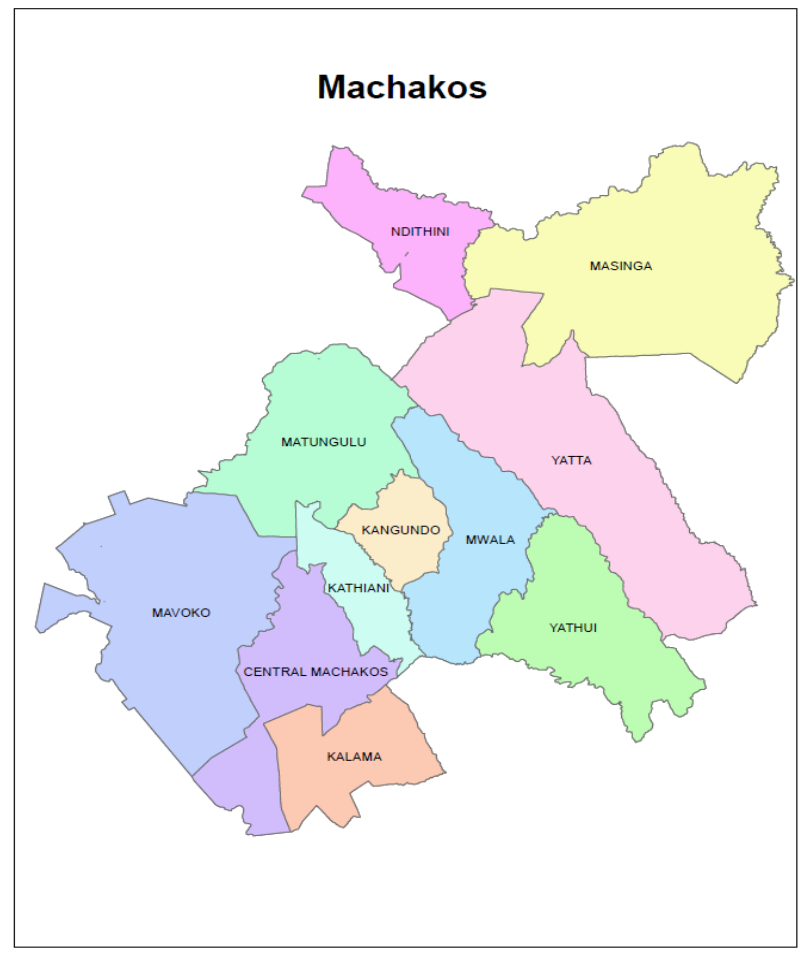

Figure 2 Geographical coverage area

From the project baseline household survey, we found that almost half of the sample household are credit rationed (We followed Boucher et al. 2008 to elicit credit rationing status of the farmers). Interestingly, $42 \%$ of the household are risk-rationed who voluntarily withdraw themselves from the credit market. RCC mechanism is very relevant for this population because RCC tool can bring these population into the credit market by acting as a substitute for collateral. 


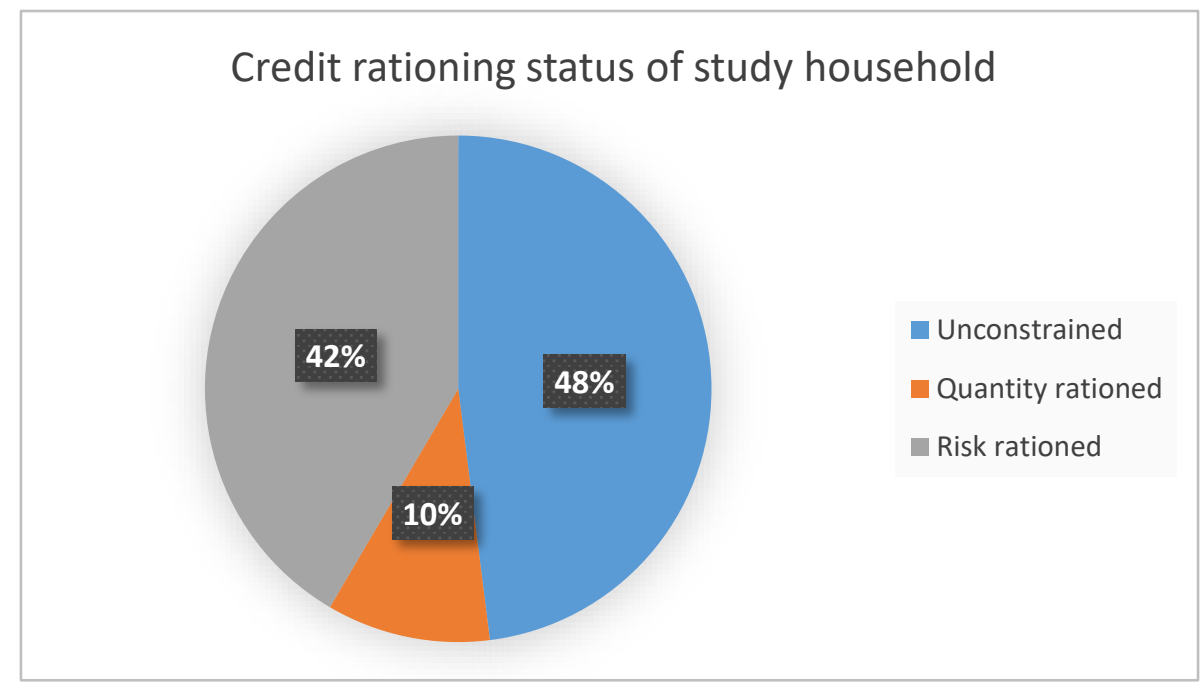

Figure 3 Credit rationing status of study household (Source: project household survey)

We analyze Climate Hazards Group InfraRed Precipitation with Station Data (CHIRPS) supported by National Aeronautics and Space Administration (NASA) and National Oceanic and Atmospheric Administration (NOAA). 5km dekadal (10-daily) CHIRPS rainfall (satellite validated with station data) data from 1981 to present are extracted from http://chg.geog.ucsb.edu/data/chirps/. CHIRPS data are extracted every 10 days, i.e., 3 values per month, for each pixel that falls into the contract coverage sub-county. These values are accumulated over long rains (Oct 15-Jan 15) and short rains (Mar 15-May 15) to represent cumulative rainfall conditions of a sub-county over a season. Hence, this measure is the best practical indicator of a drought situation in marginal areas. Loan period extends from September 12017 to May 152018 (8 months). In discussions with farmers the rare events occur about 1 in 10 years, with hardship years about 15 in every 100 years. There is no discernable pattern to the failure of the rains. Figure 4 illustrates the rainfall pattern for Central Machakos between 1981 and 2016 for long and short rains. 
We estimate using Monte Carlo methods that rainfall will fall below $114.59 \mathrm{~mm}$ and $94.14 \mathrm{~mm}$ for long and short rains in 15 of every 100 years $\left(15^{\text {th }}\right.$ percentile $)$ as marked.

Breaching the $114.59 \mathrm{~mm}$ mark occurred in about 5 of 34 years for long years or about $14.7 \%$ of years, while it breached the $94.14 \mathrm{~mm}$ mark for short rains about 6 times in the 35 -year period for about $17 \%$ of years.

We see no discernable patterns in the magnitudes of rainfall year-to-year. Simple regressions marked in Figure 4 show that there is no statistical relationship between rainfall and years for both long and short rain. The regressions are;

$$
\begin{aligned}
& L R=201.94-0.3903 \text { Year }, R^{2}=0.0027 \\
& S R=164.17-0.8444 \text { Year }, R^{2}=0.0317
\end{aligned}
$$

Both regressions suggest a decrease in rainfall over time, but these are not meaningful in a statistical sense. The low $R^{2}$ values indicate that changes across time offers no explanation for rainfall patterns. 


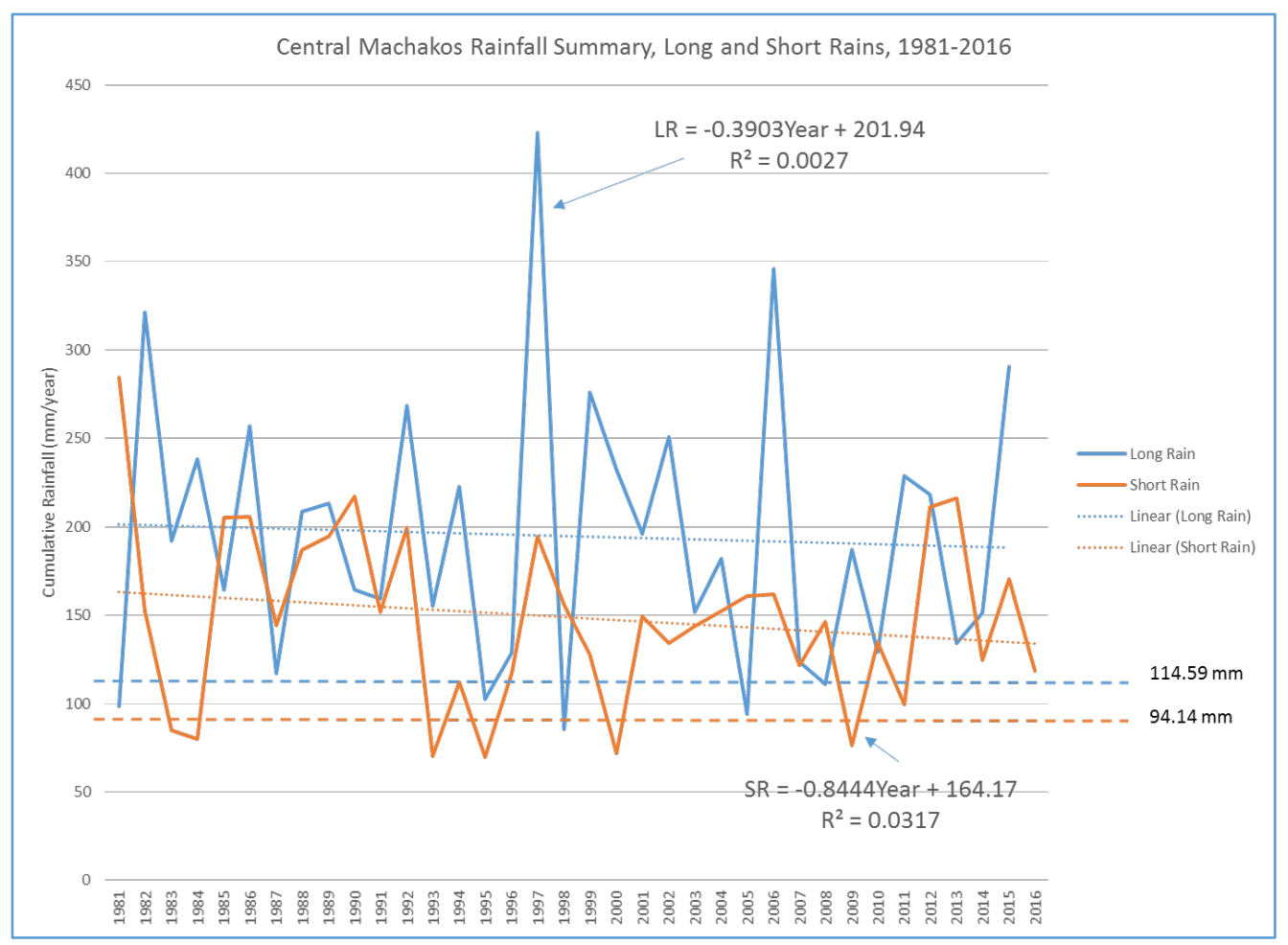

Figure 4 Central Machakos Rainfall Summary, Long and Short Rains, 1981-2016

Further, we compute in a following section the correlations between long and short rains and find the correlations to be weak. In other words, if rainfall is low in the long rain it is not jointly probable that rainfalls will also be lower in the short rains. On the other hand, correlation assessment shows that the rainfall totals across all 11 regions are highly correlated within the long rain period and within the short rain period, but not between long and short rains.

\section{Monte Carlo Simulation and validation of PERT model}

Statistical independence in year-over-year cumulative rainfall measures supports our use of Monte Carlo simulation methods to measure weather risks, establish and compute the indemnity structure, and compute interest rates on RCC. Using the distribution fitting tool in @RISK (www.palisade.com) the best-fit probability distribution for virtually all regions across both long 
and short rains is the PERT distribution. The PERT distribution is a 3-parameter distribution fit to the lowest rainfall, most likely rainfall, and highest rainfall recorded ${ }^{2}$. It is appealing because it is bounded by the historical record and does not drift off to zero or infinite in the tails as other distributions do. This important property ensures that probabilities below a target are not overstated and therefore do not introduce bias into indemnity structures and RCC interest rate measures. An example of PERT distribution for long and short rains at Central Machako is provided in Figure 5.

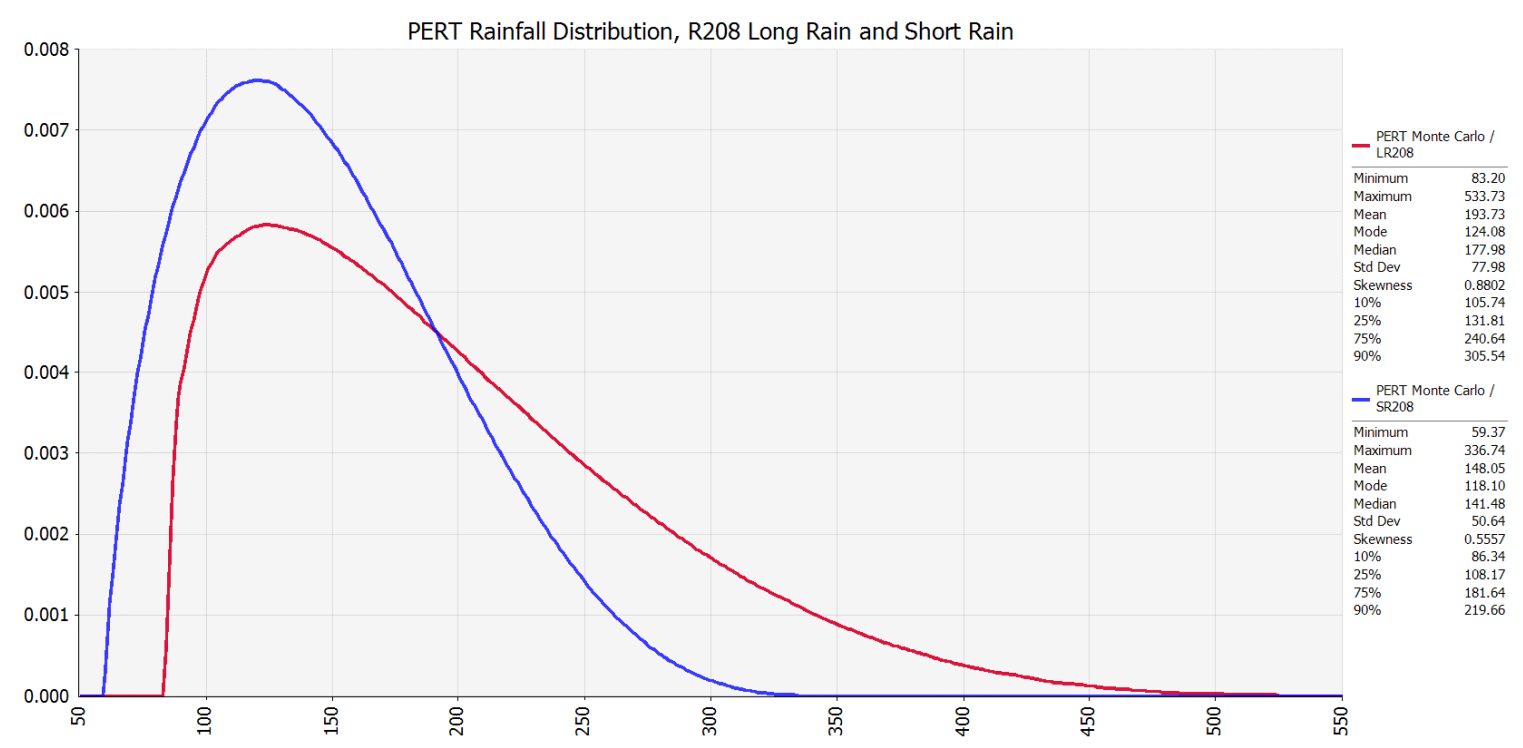

Figure 5 PERT Distribution of Long and Short Rains, Central Machakos (coded R208), 1981-2016

\footnotetext{
${ }^{2}$ The PERT distribution ('Program Evaluation Research Task') was developed originally by Malcolm et al (1959). In our context we define the highest cumulative rainfall as $b$, the lowest rainfall as a, and the modal rainfall, $\mathrm{m}$. The standard deviation of these rainfall measures is assumed to be $\sigma=\frac{1}{6}(b-a)$. Assuming further that the underlying generating process is a beta distribution, $f(y)=K(\bar{y}-a)^{\alpha_{1}}(b-\bar{y})^{\alpha_{2}}$, with $\alpha_{1}=\frac{(\bar{y}-a)(2 m-a-b)}{(m-\bar{y})(b-a)}$ and $\alpha_{2}=\frac{\alpha_{1}(b-\bar{y})}{\bar{y}-a}$. Combined, mean rainfalls are defined by $\bar{y}=\frac{a+4 m+b}{6}$.
} 


\subsection{Validation of PERT Distribution}

Although use of the PERT distribution is not foreign to financial and applied economics analysis (e.g. Clop-Gallart and Juárez-Rubio 2007, Bewley et al. 2010, Turvey et al. 2013) its use is not wide spread. Yet in instances with limited data, or with bounded distribution that do not consistently fit any particular type of distribution, the shape flexibility of PERT has its advantages. We illustrate the fit for four of the sub-counties in Machakos in Figure 6, going clockwise, for Central Machakos, Yathui, Yatta and Masinga. The respective goodness of fit using the Akaike Information Criterion (AIC) is 400.97, 414.09, 413.57. and 416.58 indicating that the degree of fit for these four districts are quite close.

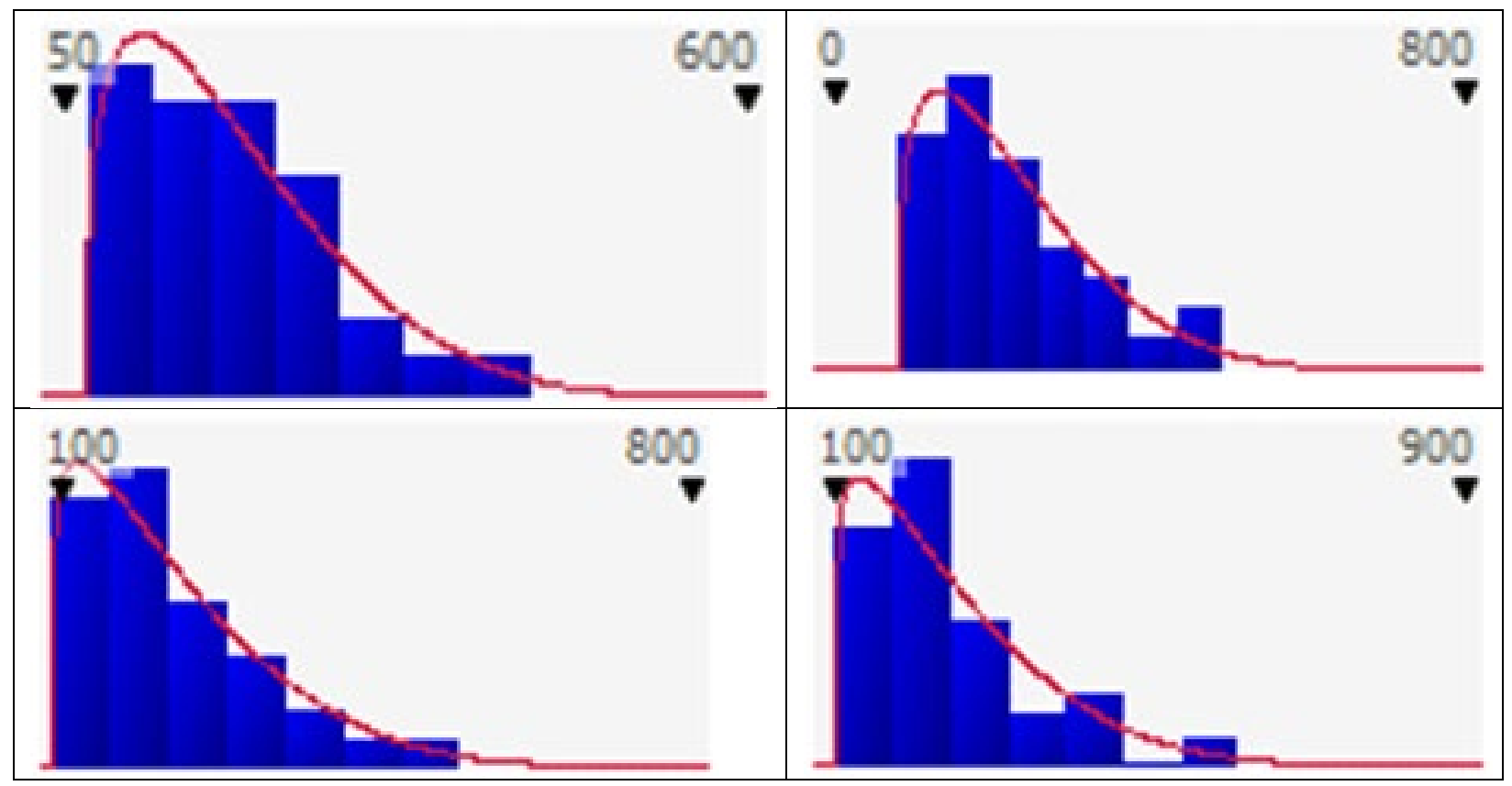

Figure 6: Distribution of PERT Distribution to Actual Cumulative Rainfall 1983-2016.. Top Left, Central Machakos, Top Right Yathui, Botton Left, Yatta, Bottom Right Masinga. (Source: by authors, generated from @RISK, Palisade Corporation)

\subsection{Evaluating PERT Against Seasonal ARIMA Alternative}

Because the PERT distribution has not been widely used in economic analysis generally, and weather insurance particularly we undertook several validation exercises to examine alternative mechanisms for pricing the insurance. Several papers in the literature have developed various 
time series models to price weather insurance (Alaton, et al. 2002; Campbell and Diebold 2003; Richards at al. 2004; Cao and Wei 2004; Turvey 2005). To determine whether time series models could be used instead of the PERT we also examined a (non-differenced) seasonal ARIMA model, $\operatorname{SARMA}(p, q)(P, Q)$, where $\mathrm{p}$ is a parameter for the non-seasonal AR model, $\mathrm{q}$ is a parameter for the moving average component, $\mathrm{P}$ and $\mathrm{Q}$ indicate the parameters for seasonal patterns. With seasonality being a regular pattern that repeats over a fixed number of time periods (s), the SARMA model can be written as:

$$
\begin{aligned}
& \left(1-\phi_{1} L^{1}-\ldots-\phi_{p} L^{p}\right)\left(1-\Phi_{1} L^{s}-\ldots-\Phi_{P} L^{s P}\right) Y_{t} \\
& =c+\left(1-\theta_{1} L^{1}-\ldots-\theta_{q} L^{q}\right)\left(1-\Theta_{1} L^{s}-\ldots-\Theta_{Q} L^{Q}\right) u_{t}
\end{aligned}
$$

where $u_{t}$ is a white noise process. Ultimately, we used 12-month differencing to capture year over year, same-date measures. This was important to capture whether the within-season distribution was stable year over year. Differencing in this way converted the SARMA model to its integrated form SARIMA. The autocovariance function deployed in this for the time series analysis captured whether or not there was some underlying path dependency between the rainy season and the months and days leading up to it. An Augmented Dickey-Fuller test confirmed that the raw data was stationary, so it was not critical to difference on a day-to-day basis.

Unfortunately, the SARIMA model failed, as did several variants. The biggest statistical issue is that the integrated moving average component is designed to smooth the dynamic daily path. But in doing so it also reduces variance around the predicted value. When pricing insurance with indemnities triggered at the $15^{\text {th }}$ or $20^{\text {th }}$ percentile, it is critical that the lower partial moments be preserved. Using out-of-sample forecasts with 5000 Monte Carlo replications, the trigger level for all sub-countires are presented in Table 1 for the Long rains. For Kathiani and 
Ndithini the trigger levels at $20 \%$ were reasonably close but for most others the triggers were too far off to be of any value. Central Machakos had a SARIMA prediction of $90.7 \mathrm{~mm}$ against the PERT trigger of $120.5 \mathrm{~mm}$, Yatta had SARIMA of $236.3 \mathrm{~mm}$ against the PERT measure of $145.2 \mathrm{~mm}$.

Table 1 Cumlative Rainfall Trigger Levels from PERT and SARIMA Models (mm)

\begin{tabular}{lccccccccccc}
\hline & $\begin{array}{c}\text { Central } \\
\text { Machakos }\end{array}$ & Yathui & Yatta & Masinga & Matungulu & Kalama & Kathiani & Mwala & Kangundo & Ndithini & Mavoko \\
\hline \hline PERT 20\% & 120.5 & 141.9 & 145 & 186.7 & 143.2 & 137.2 & 118.9 & 132.2 & 109.5 & 105.9 & 122.1 \\
SARIMA 20\% & 90.7 & 171.8 & 235 & 280.2 & 134.5 & 93.4 & 115.7 & 164 & 134.6 & 103 & 59 \\
\hline
\end{tabular}

\subsection{Validating PERT with Seasonal Differencing}

While we had to rule out any form of time series modeling, the year-over-year differencing exercise provided support for the PERT model. If the PERT model is correct in terms of variance and skewness, for example in taking the difference in rainfall measured on October $15^{\text {th }}$ between 2016 and 2015, and again between 2015 and 2014 and so on, and then repeated this for each day between October $15^{\text {th }}$, then the within-season distribution of these differences should center on zero. Figure 7 illustrates four of these distributions, going clockwise, for Central Machakos, Yathui, Yatta and Masinga. The top-left figure for Central Machakos also provides the kernel estimate of the difference distribution and a normal plot. The mode of both centered on zero. There were, of course, year over year differences as one would expect with such data, but the distributions being centered on zero across all days suggests strongly that the mean, variance, and skewness of our PERT approximations is very stable. 


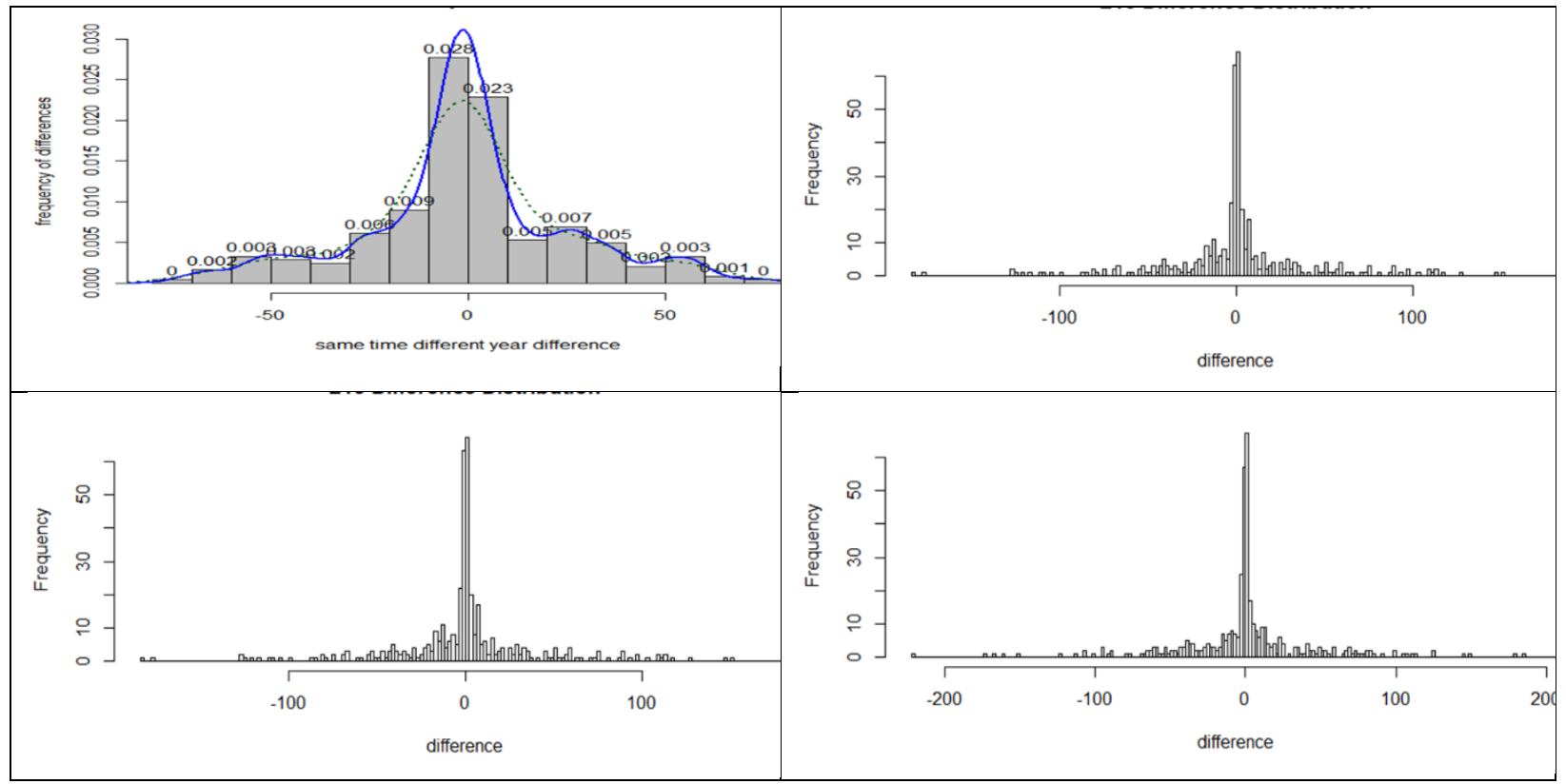

Figure 7: Distribution of Year-Over-Year, Same-Day Differences. Top Left, Central Machakos, Top Right Yathui, Botton Left, Yatta, Bottom Right Masinga. (Source, Li, Yan (2018) "A Comparison between PERT Distribution and Seasonal ARIMA Model to Forecast Rainfall Patterns" Unpublished MS Thesis, Dyson School of Applied Economics, Cornell University, May 2018),

\section{Empirical rating of RCC}

This section provides the rating methodology as applied to the rating model in the previous section. It describes a) the selection of rainfall trigger or strike, b) the calculation of the tick value, c) the computation of indemnities, and d) the imputation of RCC interest rates to be charged on the loans. On this latter point we explore two approaches to interest rate determination. The first is the interest rate to be charged if the insurer is willing to be paid the premium at the time the loan is repaid (ex post) and the second is if the insurer requires receipt of insurance premiums up front (ex-ante). 


\subsection{Determining Rainfall Triggers}

The first step is to determine the rainfall triggers. As mentioned we use Monte Carlo simulation techniques across correlated PERT distributions uniquely defined for each region in both long and short rain seasons. Upon discussions with farmers and extension experts we are recommending that rainfall triggers be based on the rainfall recorded at the $15^{\text {th }}$ percentile. This suggests that farmers would receive payouts from either the long rains or short rains (and possibly both) on average, about once in every 6.7 years. Because of differences in location and altitude, the records show that minimum, maximum, and most likely rainfalls differ across regions. To avoid excessive basis risk in rainfall measurement we have determined it best to provide rainfall coverage at the regional or district level, rather than the Machakos region as a whole. Thus, we have 22 different rainfall triggers each determined by 22 uniquely defined PERT distributions, covering each of 11 districts, across the 2 seasons.

Figure 8 shows the simulation output for long rains in Central Machakos showing minimum recorded rainfall of $83.2 \mathrm{~mm}$, and trigger rainfall of $114.6 \mathrm{~mm}$ imputed from 15 th percentile of PERT distribution. In this case, the trigger is $114.6 \mathrm{~mm}$, and RCC indemnities would not be triggered unless cumulated rainfall between October 15 and January $15^{\text {th }}$ fell below this level, i.e. $\operatorname{Max}\left(0, Z_{i}-R_{i}\left(t_{i}, T_{i}\right)\right)=\operatorname{Max}(0,114.6-R(10 / 15,01 / 15))$. For example, if the actual rainfall was only $100 \mathrm{~mm}$ then the rainfall deficit on which the loan indemnity would be paid is $14.6 \mathrm{~mm}$. However, if the actual rainfall was $150 \mathrm{~mm}$, then no indemnity would be paid. 


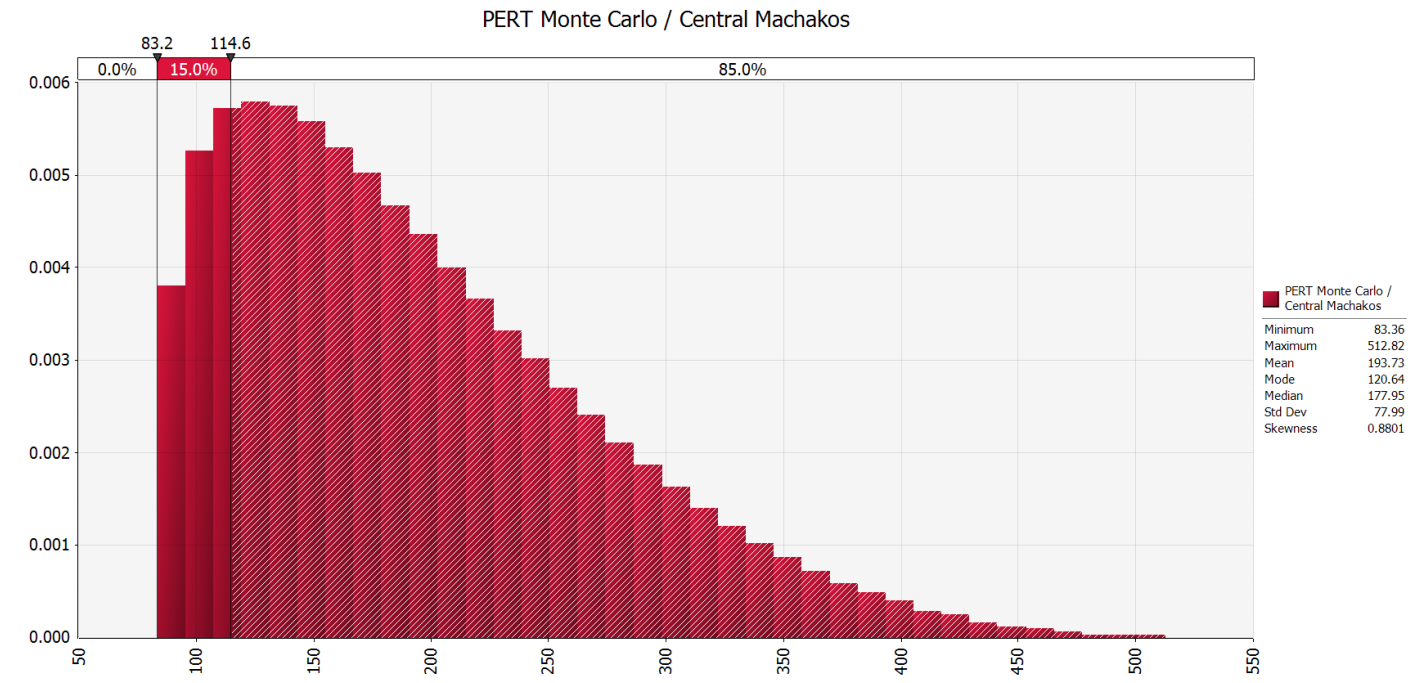

Figure 8 Simulation Output for Long Rains in Central Machakos showing Minimum recorded rainfall of 83.2mm, and Trigger Rainfall of $114.6 \mathrm{~mm}$ Imputed from 15th Percentile of PERT Distribution

Figure 9 shows the suggested rainfall triggers for long and short rains and for each of the 11 target regions. All triggers are computed at the $15^{\text {th }}$ percentile, and all are drawn from jointly distributed PERT distributions (i.e. correlated across space and time).

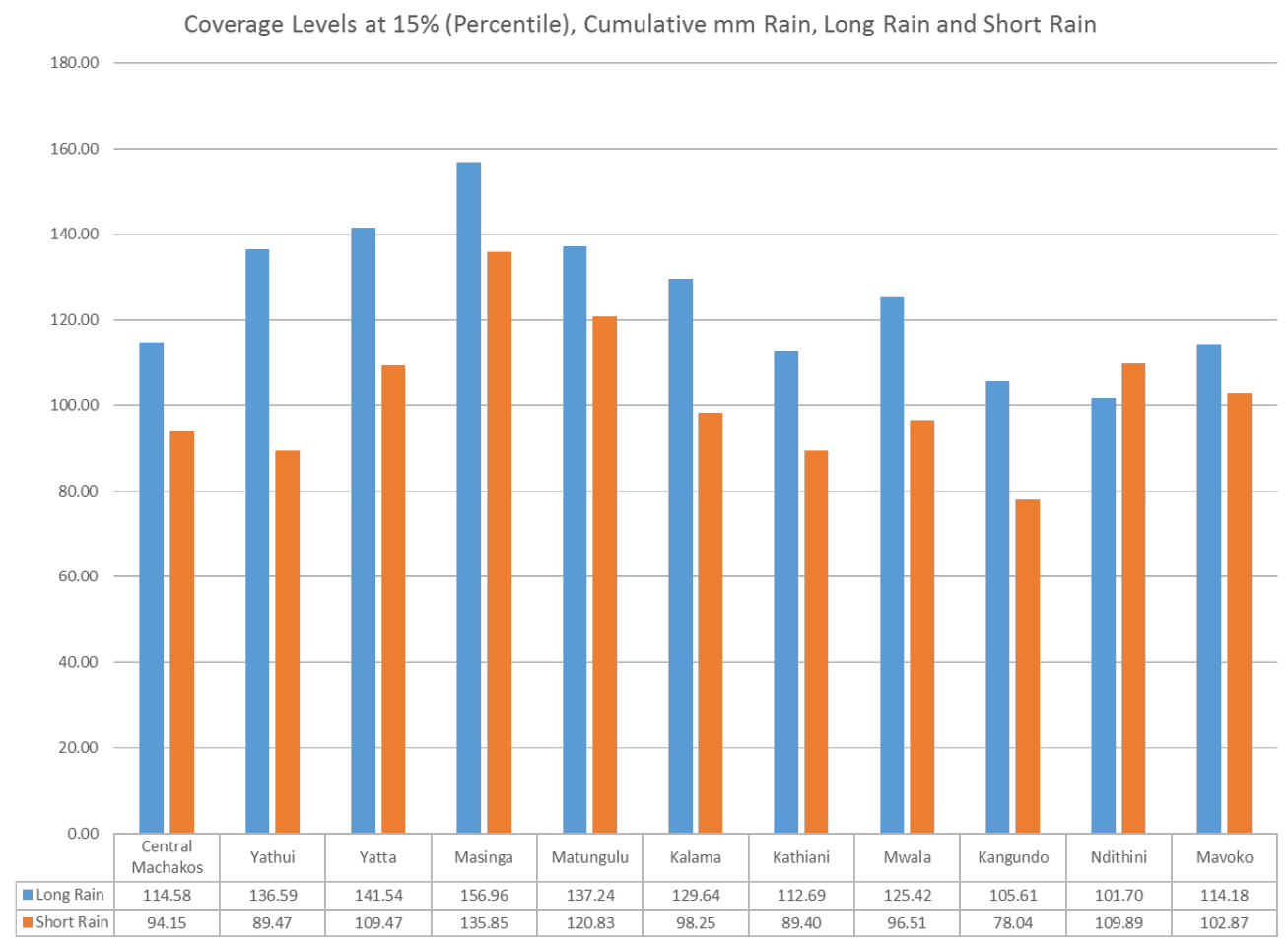

Figure 9 Coverage Levels at 15\% (Percentile), Cumulative mm Rain, Long Rain and Short Rain 


\subsection{Determining the Tick Value}

The conversion of rainfall shortfalls in mm to Kenyan Shillings is done using a 'tick' conversion. We assume a 10,000 Ksh loan for convenience. This is scalable in the sense that a 50,000 Ksh loan would pay 5-times the indemnity in nominal terms, but ultimately the interest rate charged on RCC loans is independent of loan amount.

The tick conversion is computed using

$$
\psi_{i}=\frac{f}{Z_{i}-\operatorname{Min}\left(R_{i}\left(t_{i}, T_{i}\right)\right)}=\frac{10,000 \mathrm{Ksh}}{114.6 \mathrm{~mm}-83.2 \mathrm{~mm}}=318.47 \mathrm{Ksh} / \mathrm{mm} .
$$

We use the minimum recorded rainfall values from the history available to us. Beyond the pilot program it may be determined that loan coverage should occur at a higher rainfall amount. For now, however, our design is to ensure that if rainfall is no more than $83.2 \mathrm{~mm}$ then the full loan principal is recovered by the insurance policy. Although we recommend setting triggers at the $15^{\text {th }}$ percentile as discussed above, there may be occasion where a product might be reduced to the $10^{\text {th }}$ percentile with a lower frequency payout, or at the $20^{\text {th }}$ percentile with a higher frequency payout.

Figure 10 illustrates the average triggers and tick across all 11 sub-counties for different percentile selection criteria. The rainfall triggers are recorded on the right axis and show the increase in trigger corresponding to increased percentile. The left axis shows the tick values. The tick values are decreasing but at a decreasing rate. In all cases they are anchored to the minimal rainfall recorded. Regardless of coverage, and corresponding tick values, the maximum indemnity cannot exceed the base 10,000 Ksh loan. 


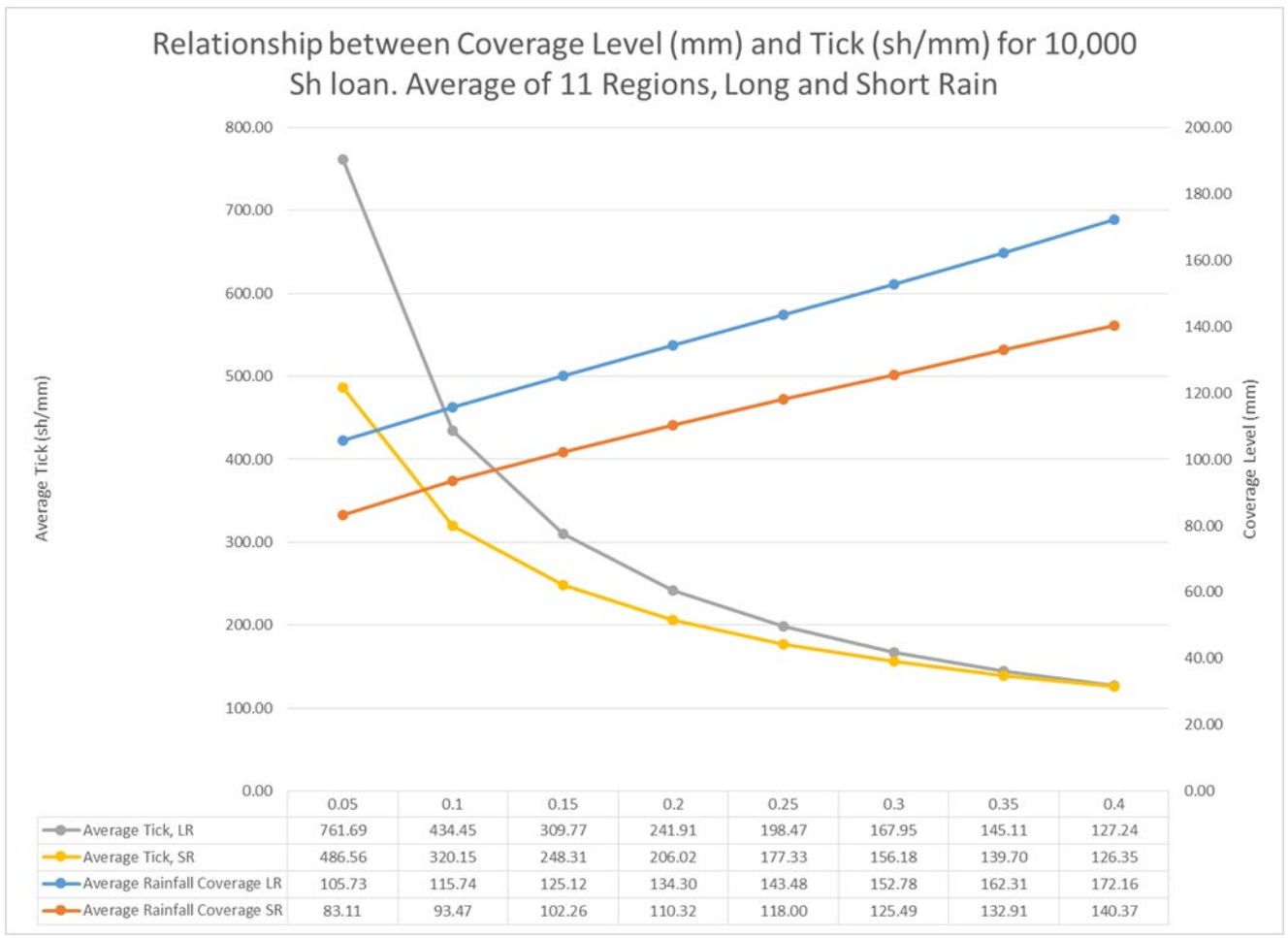

Figure 10 Relationship between Coverage Level $(\mathrm{mm})$ and Tick (sh/mm) for 10,000 Sh loan. Average of 11 Regions, Long and Short Rain

\subsection{Calculation of Indemnities and Insurance Premiums}

The indemnity is calculated by multiplying the tick, by the rainfall shortfall. For example, if the actual rainfall in Central Machakos is $100 \mathrm{~mm}$, the shortfall is $14.6 \mathrm{~mm}$. Each $\mathrm{mm}$ receives 318.47 shillings so that the indemnity paid on a $10,000 \mathrm{Ksh}$ loan would be $4,649.66 \mathrm{Ksh}$. The farmer would have to pay only $5,350.34 \mathrm{Ksh}$ plus interest. If measured rainfall is $150 \mathrm{~mm}$ there would be no payout, but if rainfall is $83.2 \mathrm{~mm}$ or lower than the rainfall shortfall of $(114.6-83.2)$ $31.4 \mathrm{~mm}$ times the tick of 318.47 exactly equals $10,000 \mathrm{Ksh}$.

These indemnities are calculated for both the long and short rains. While it may be possible to offer insurance only for long rain or only for short rain, our indemnity structure for this pilot program is based on payments from either or both. In either case the maximum indemnity is $10,000 \mathrm{Ksh}$. 


$$
I=\operatorname{Min}\left(10000, \psi_{L}\left[\operatorname{Max}\left(0, Z_{L}-R_{L}\left(t_{L}, T_{L}\right)\right)\right]+\psi_{S}\left[\operatorname{Max}\left(0, Z_{S}-R_{S}\left(t_{s}, T_{s}\right)\right)\right]\right) .
$$

Figure 11 shows the average of the expected indemnities across all 11 regions, by percentile. At the $15^{\text {th }}$ percentile

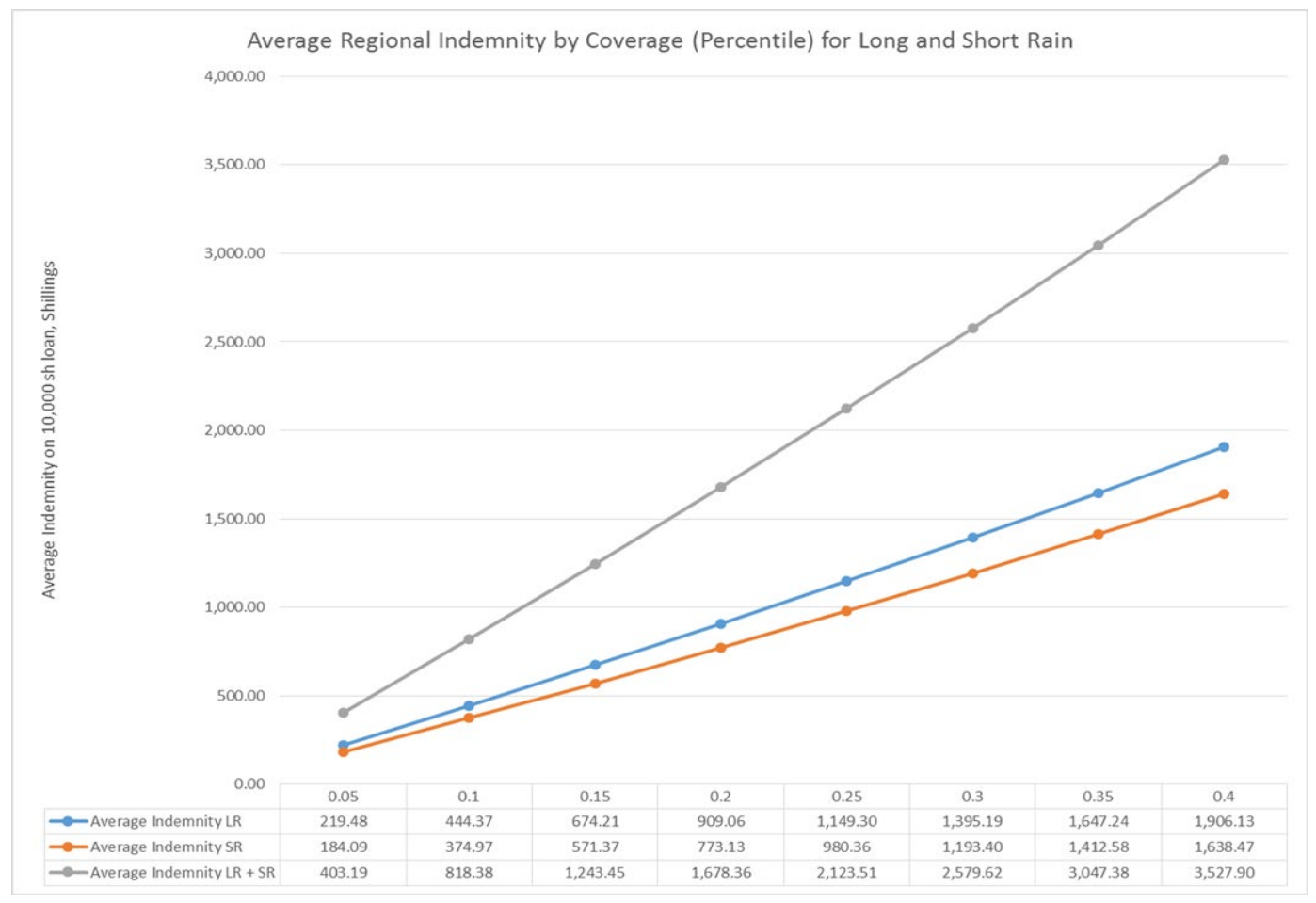

Figure 11 Average Regional Indemnities by Coverage Level

On average the $15^{\text {th }}$ percentile indemnities are $674.21 \mathrm{Ksh}$ for long rains, $571.37 \mathrm{Ksh}$ for short rains and 1,243.45 for combined long and short rains, including years in which indemnities are collected on both. In general, these suggest that across years indemnities can be expected to cover $6.74 \%, 5.71 \%$, and $12.43 \%$ of loan principle meaning on average that farmers would expect to pay about $93.25 \%, 94.29 \%$, and $87.57 \%$ of loan principal plus interest. In comparison if the $40^{\text {th }}$ percentile was selected, with a payment about 2 of every 5 years, the insurer could expect to pay in indemnities about $35.28 \%$ of loan principal, while farmers would expect to pay 
on average about $64.72 \%$ of loan principal. Of course, with high frequency events, insurers would anticipate higher premiums and farmers would expect to pay much higher risk premiums on their RCC loan interest rates.

\section{Insurance Loading}

We use a $25 \%$ loading, $\delta=0.25$, on expected indemnities to cover administrative, underwriting, and settlement costs. The load-adjusted indemnity is given by

(14) $v=E\left[\operatorname{Min}\left(10000, \psi_{L}\left[\operatorname{Max}\left(0, Z_{L}-R_{L}\left(t_{L}, T_{L}\right)\right)\right](1+\delta)+\psi_{S}\left[\operatorname{Max}\left(0, Z_{S}-R_{S}\left(t_{s}, T_{s}\right)\right)\right](1+\delta)\right)\right]$

\subsection{Imputing RCC Interest Rates}

There are two approaches to computing RCC interest rates. The first is what we refer to as expost pricing which is based on the insurer getting paid for the premium at the time that the loan is repaid. The second, is ex ante in which the insurer is paid in advance. In the ex-ante approach the insurer is paid the premium up front and the premium is added to the base loan amount.

\section{Interest Rate on Ex Post Risk Contingent Credit}

As previously derived the formula used to impute the interest rate is given by

$$
i^{*}=\frac{\ln \left[\frac{E\left[\psi_{L}\left(Z_{L}-R_{L}\left(t_{L}, T_{L}\right)\right)(1+\delta)+\psi_{S}\left(Z_{S}-R_{S}\left(t_{s}, T_{s}\right)(1+\delta)\right)\right]}{f}+e^{\left(i^{* *}\right) T}\right]}{T}
$$

Based on the average values for all 11 regions, use of the formula (15) can be illustrated following 


$$
\begin{aligned}
& \psi_{L}=309.77 \mathrm{Ksh} \\
& \psi_{S}=248.31 \mathrm{Ksh} \\
& \delta=0.25 \\
& f=10,000 \mathrm{Ksh} \\
& i^{* *}=12 \% \\
& T=8 \text { months }=.667 \text { years } \\
& E\left[\psi_{L}\left(Z_{L}-R_{L}\left(t_{L}, T_{L}\right)\right)\right](1+\delta)=309.77\left(125.12-R_{L}\left(t_{L}, T_{L}\right)\right)(1+.25)=674.22 \mathrm{Ksh} \\
& E\left[\psi_{S}\left(Z_{S}-R_{S}\left(t_{s}, T_{s}\right)\right)\right](1+\delta)=248.31\left(102.26-R_{S}\left(t_{s}, T_{s}\right)\right)(1+.25)=571.37 \\
& \quad \ln \left[\frac{1,243.53}{10,000}+e^{0.12 \times 0.667}\right] \\
& i^{*}=\frac{{ }_{0} .667}{2}=32.14 \%
\end{aligned}
$$

\section{Interest Rate on Ex Ante Risk Contingent Credit}

With ex-ante risk contingent credit, the insurer is paid the insurance premium up front. This premium, measured in terms of the expected indemnity is added to the base loan. The formula for computing ex ante interest rates is given by

$$
i^{*}=\frac{\ln \left[\frac{(f+I) e^{i^{*} T}}{f}\right]}{T}
$$

Using the same values as above,

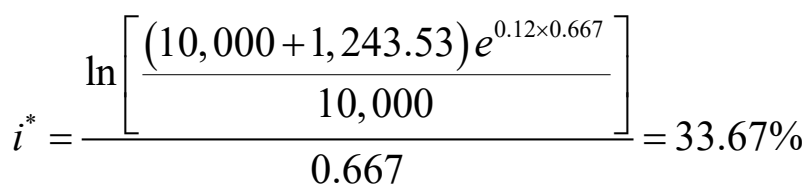

As expected the interest rate on the ex-ante model is slightly higher than the ex post model because of the additional compounding of interest on the up-front indemnity.

Figures 12 and 13 summarize the final simulated results for interest rates on RCC. Figure 9 summarizes ex-post results, while Figure 10 summarizes ex ante results. The ex-ante results 
which assumes that insurance premiums are posted at the time the loan is made and added to loan principal are about $1.5 \%$ points higher.

The three bars in Figures 9 and 10 represent three separate models; Only long rains are insured, only short rains are insured and both long and short rains are insured. Our interest is in the combined model, although either the long rains or the short rains could be priced and insured separately. The interest rates for the combined insurance are naturally higher because it is possible that indemnities can be received from both sources. Although correlations between long and short rains are weak, they still have some effect on joint outcomes.

Because of the nature of insurance markets, it is likely that the insurer would need to be paid upfront, so we will only focus on the ex-ante model. Interest rates are remarkably consistent across regions, with only slight variations due to different weather risks. The interest rates range from $32.51 \%$ in Mavoko to $35.11 \%$ in Yatta. Recall that the base interest rates for basic loans is $12 \%$ and that these interest rates include a $25 \%$ loading factor. Beyond the loading factor they are actuarially sound. 


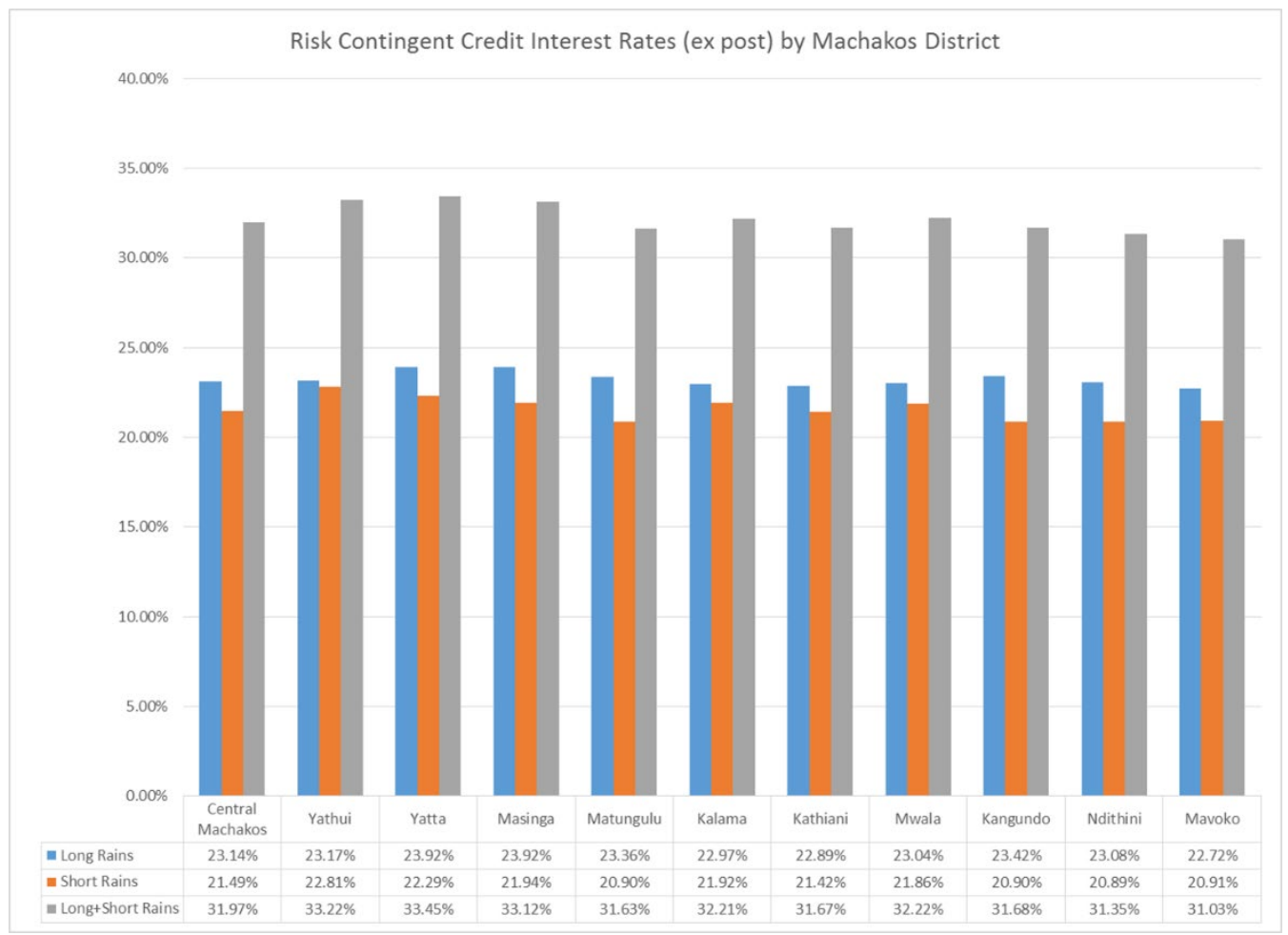

Figure 12 Risk Contingent Credit Interest Rates (ex post) by Machakos District 


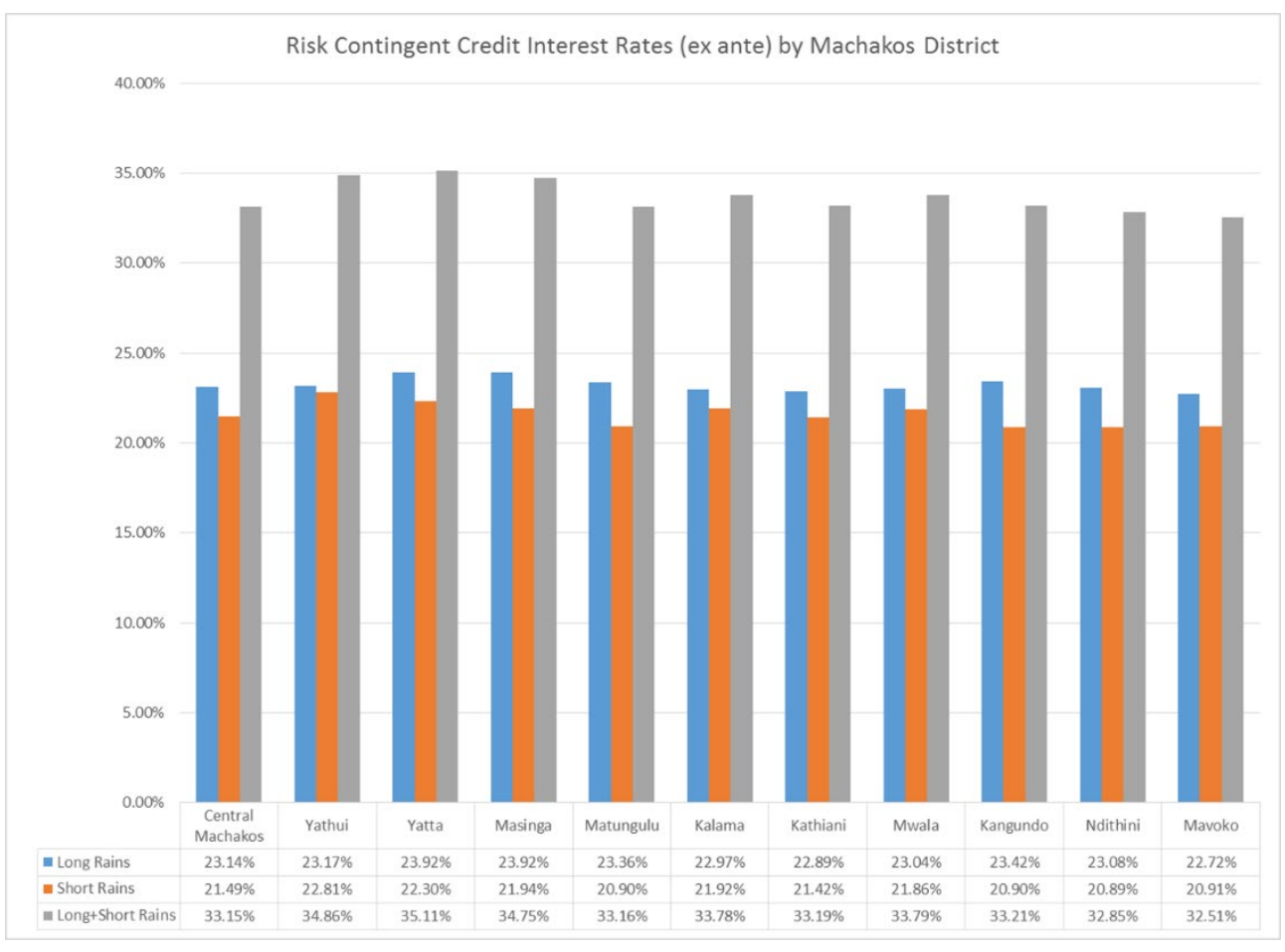

Figure 13 Risk Contingent Credit Interest Rates (ex-ante) by Machakos District

\subsection{Indemnities}

Covariate risks are important considerations for any insurance product. If the failure in rains is significant in one district it is highly likely that the rains have failed also in other districts. This section provides an overview of the frequency of payments and number of regions likely to receive payments. This does not speak to the magnitude of payments which, capped at 10,000 Ksh, are discussed separately.

The frequency of payouts, determined from Monte Carlo simulations are summarized in Table 2 . For long rains the probability that no district will receive an indemnity is $75.16 \%$, for short rains $72.41 \%$ and there is a $55.9 \%$ chance that neither long nor short rains will receive an indemnity. This latter probability is equivalent to saying that at least one district will receive an indemnity in either long or short rains $40.1 \%$ of the time, or at least once every 4 years. 
Table 2 Frequency of Regions Receiving Indemnity in a Season

\begin{tabular}{l|lll}
$\begin{array}{r}\text { Number } \\
\text { of }\end{array}$ & $\begin{array}{l}\text { Long } \\
\text { Rain }\end{array}$ & $\begin{array}{l}\text { Short } \\
\text { Rain }\end{array}$ & $\begin{array}{l}\text { Long } \\
\text { and/or } \\
\text { Short } \\
\text { Rain }\end{array}$ \\
\hline 0 & & & $55.90 \%$ \\
1 & $75.16 \%$ & $72.41 \%$ & $6.07 \%$ \\
2 & $3.86 \%$ & $5.02 \%$ & $4.14 \%$ \\
3 & $2.27 \%$ & $3.19 \%$ & $2.83 \%$ \\
4 & $1.74 \%$ & $2.11 \%$ & $2.40 \%$ \\
5 & $1.31 \%$ & $1.65 \%$ & $1.97 \%$ \\
6 & $1.11 \%$ & $1.34 \%$ & $2.02 \%$ \\
7 & $1.03 \%$ & $1.32 \%$ & $2.33 \%$ \\
8 & $1.31 \%$ & $1.39 \%$ & $2.63 \%$ \\
9 & $1.33 \%$ & $1.67 \%$ & $3.09 \%$ \\
10 & $1.53 \%$ & $2.03 \%$ & $3.85 \%$ \\
11 & $2.21 \%$ & $2.10 \%$ & $12.81 \%$
\end{tabular}

That drought conditions are so severe that all 11 districts receive an indemnity in one year is rare. There is only a $7.17 \%$ chance that all 11 districts would receive an indemnity in long rains, $5.8 \%$ chance for short rains, and a $12.81 \%$ chance that all districts would receive indemnities in either long or short rains. In other words, in about 13 of every 100 years it can be expected that the insurer will pay indemnities in all districts for either the long or short rains.

Figure 14 illustrates the conditional probabilities by Baye's rule on the frequency of indemnities given that at least 1 district receives an indemnity. It is U-shaped as expected because of the high degree of correlation amongst rainfalls. At the lower end the probability that only 1 district receives a payment in either long and short rains is $13.76 \%$. A season in which only 1 or a few districts receive indemnities comes about by chance. This will arise as a result of uncorrelated weather patterns or weather patterns that are not wide-spread across the regions. On 
the other hand, Figure 14 shows the significant of covariate risks. Given that at least one district receives an indemnity there is a $28.86 \%$ chance that all 11 districts will receive a long rain indemnity; a $21.02 \%$ chance that all districts will receive a short rain indemnity, and a $29.03 \%$ chance that all 11 districts will receive an indemnity in either the long rain or short rain.

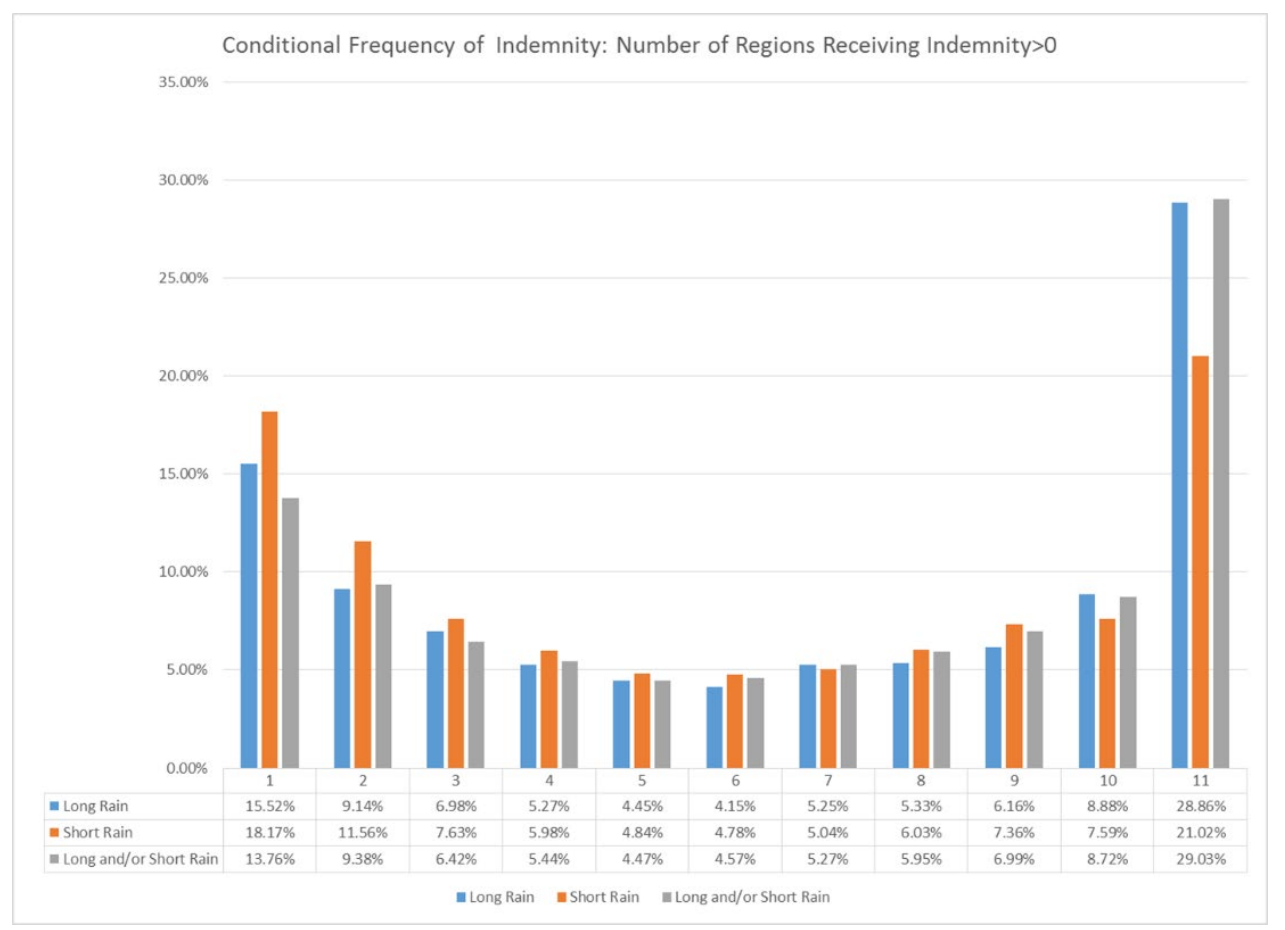

Figure 14 Conditional Probabilities of Frequency of Indemnities across Districts

Table 3 summarizes the joint distribution between number of districts receiving indemnity in long rains and receiving the stated number also receiving indemnities in the short rains. There is a $55.89 \%$ chance that no district in either long rain or short rain receives an indemnity. If there is no indemnity in the long rain there is a $3.515 \%$ chance that 1 district and $3.93 \%$ chance that all 11 districts will receive an indemnity in the short rains. Likewise, there is a $4.595 \%$ chance that all 11 districts will receive an indemnity in the long rains but 0 districts in the short rains. At the lower right of Table 2, the likelihood that a total catastrophic failure of both long and short rains 
will result in indemnities for all 11 districts in both seasons is $0.62 \%$ or about 6 in every 1,000 years.

Table 3 Joint Distribution of Number of Districts Receiving Indemnity between Long and Short Rains

\begin{tabular}{r|rrrrrrrrrrrrr}
\multicolumn{10}{c}{ Long Rains } \\
\begin{tabular}{r|rrrrrrrrrr} 
Short \\
Rain
\end{tabular} & 0 & 1 & 2 & 3 & 4 & 5 & 6 & 7 & 8 & 9 & 10 & 11 \\
0 & 55.895 & 2.505 & 1.555 & 1.065 & 0.890 & 0.680 & 0.745 & 0.955 & 0.960 & 1.005 & 1.555 & 4.595 \\
1 & 3.515 & 0.235 & 0.140 & 0.115 & 0.075 & 0.105 & 0.090 & 0.060 & 0.090 & 0.080 & 0.085 & 0.425 \\
2 & 2.245 & 0.145 & 0.085 & 0.070 & 0.055 & 0.055 & 0.030 & 0.040 & 0.040 & 0.070 & 0.070 & 0.285 \\
3 & 1.465 & 0.135 & 0.040 & 0.045 & 0.045 & 0.015 & 0.000 & 0.015 & 0.030 & 0.035 & 0.045 & 0.235 \\
4 & 1.105 & 0.080 & 0.060 & 0.050 & 0.040 & 0.025 & 0.010 & 0.030 & 0.020 & 0.035 & 0.045 & 0.150 \\
5 & 0.965 & 0.045 & 0.020 & 0.035 & 0.005 & 0.025 & 0.025 & 0.005 & 0.000 & 0.030 & 0.045 & 0.135 \\
6 & 0.935 & 0.045 & 0.050 & 0.025 & 0.030 & 0.025 & 0.010 & 0.010 & 0.035 & 0.020 & 0.025 & 0.110 \\
7 & 0.975 & 0.090 & 0.030 & 0.030 & 0.015 & 0.005 & 0.015 & 0.015 & 0.020 & 0.025 & 0.060 & 0.110 \\
8 & 1.200 & 0.075 & 0.025 & 0.060 & 0.025 & 0.020 & 0.010 & 0.025 & 0.015 & 0.040 & 0.035 & 0.135 \\
9 & 1.515 & 0.090 & 0.020 & 0.035 & 0.020 & 0.025 & 0.015 & 0.025 & 0.025 & 0.040 & 0.045 & 0.175 \\
10 & 1.415 & 0.120 & 0.065 & 0.055 & 0.035 & 0.015 & 0.025 & 0.030 & 0.020 & 0.055 & 0.065 & 0.195 \\
11 & 3.930 & 0.290 & 0.180 & 0.150 & 0.075 & 0.110 & 0.055 & 0.095 & 0.070 & 0.095 & 0.130 & 0.620
\end{tabular}

\section{Indemnity Payouts}

Core to the successful application of Risk Contingent Credit is the effective transfer of risk from lenders and borrowers to an insurer. Figure 15 shows the simulated loan repayment and indemnity transfer structure of RCC for Central Machakos with long rain coverage at the $15^{\text {th }}$ percentile. The top panel shows the loan repayment schedule for the farmer-borrower with rainfall on the $\mathrm{x}$ axis and loan repayment at the $\mathrm{Y}$-axis. The trigger for insurance indemnities is $114.6 \mathrm{~mm}$. Below this trigger the farmer's loan repayment is decreased in proportion to the rainfall deficit. If the rainfall shortfall is substantially high there is a chance that the farmer will not have to repay any principal at all, paying only the interest on the loan. 
The lower panel of Figure 15 shows the indemnity transfer to the lender. The money is deposited from the insurer into the borrower's account at the bank. The loan transfer is isomorphic to the loan repayment schedule. 


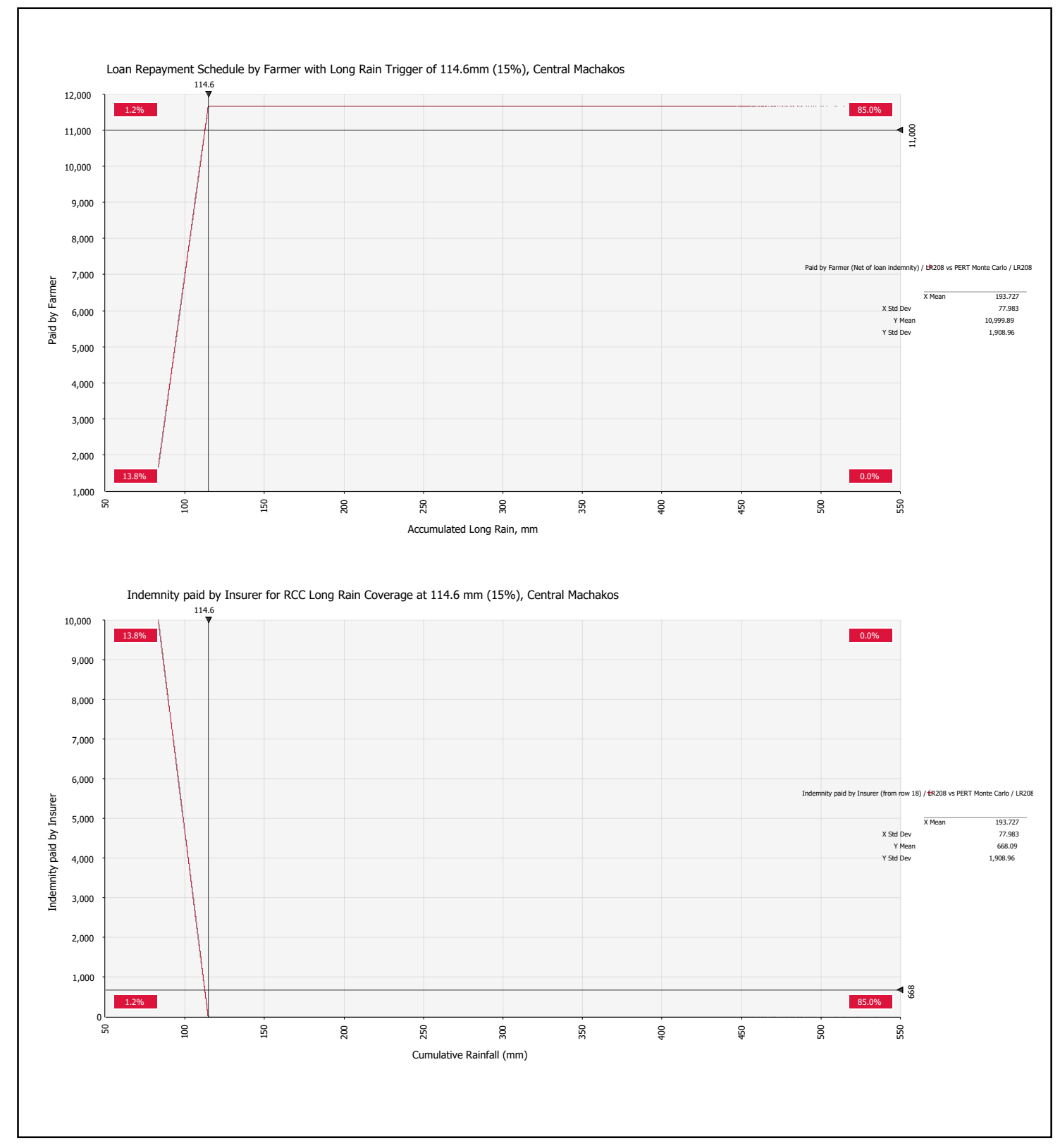

Figure 15 Simulated Loan Repayment Schedules and Indemnity Transfer 
From the banker's point of view the combined payment from the indemnity schedule plus the repayment schedule, satisfies the loan principal repayment. Figure 16 shows the iso-repayment line to the lender. The iso-repayment line shows the sources of loan repayment to lender from borrower on the $\mathrm{Y}$-axis and the insurer on the $\mathrm{X}$-axis. In this example, the loan repayment including interest is $12,376 \mathrm{Ksh}$. The vertical and horizontal lines show, e.g., that if the indemnity is 4,000 Ksh paid by the insurer, borrower pays 8,376. This dollar-for-dollar substitution assures that all combinations along the sloped line $=12,376$. This, of course, is the targeted and desired result: With assured repayment against drought risks the lender's exposure to repayment risk is virtually eliminated, which should increase the supply of credit to farmers, while the reduction in business and financial risks facing the farmer should encourage loan demand.

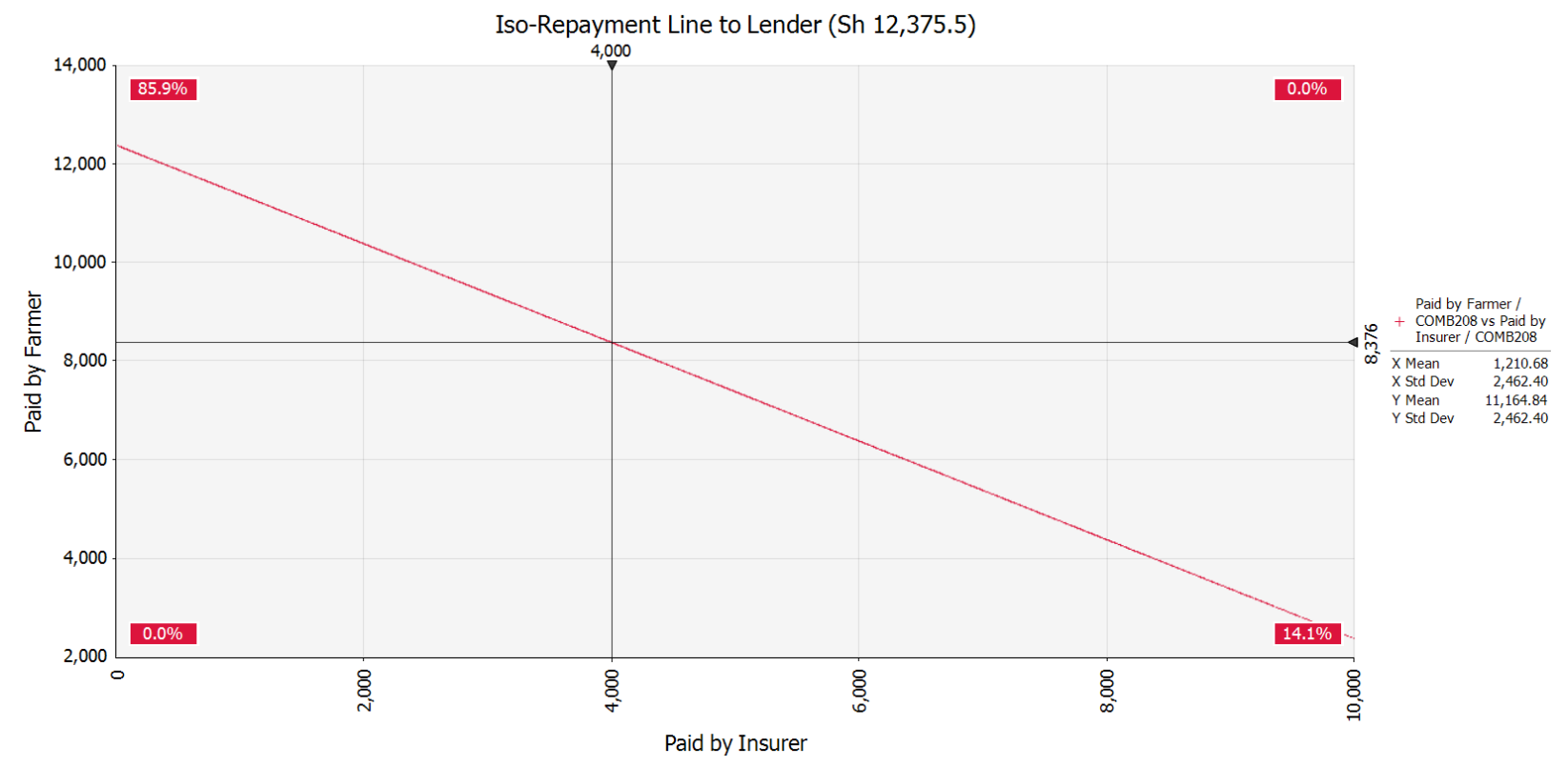

Figure 16 Iso-Repayment Line with Risk-Contingent Credit 


\section{Distribution of Indemnities}

This section reviews the relationships between RCC indemnities and loan repayment. We use as a base a 10,000 Ksh loan with indemnities arising from either long rain, short rain, or both. The numbers reported are the averages across all 11 districts. The mean payments are going to be sensitive to the trigger levels elected. Although we are recommending coverage at the $15^{\text {th }}$ percentile, Figure 17 shows the relationship between mean indemnity, mean repayment, and total loan amount with increasing coverage to the $40^{\text {th }}$ percentile. The loan amounts (principal plus interest) increase because of the increased interest rates with higher coverage.

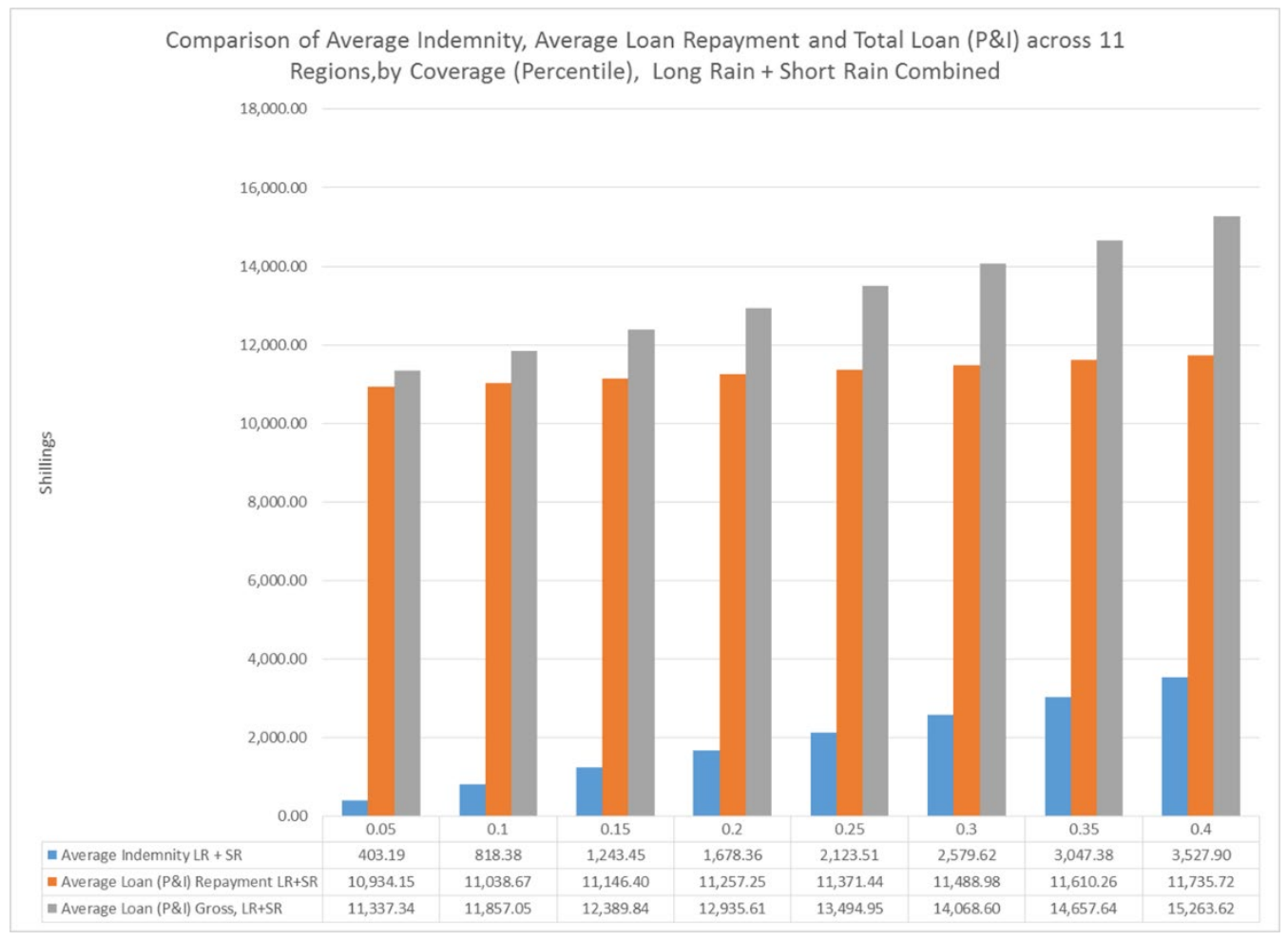

Figure 17 Comparison of average indemnity

At the lowest coverage level ( $5^{\text {th }}$ percentile) the expected indemnity would be $403.19 \mathrm{Ksh}$. The amount to be repaid is $11,337.34 \mathrm{Ksh}$ so the expected amount that the farmer woul repay is $10,934.15 \mathrm{Ksh}$. At the $15^{\text {th }}$ percentile, the insurer can expect to pay across all 11 districts about $1,234.45 \mathrm{Ksh} /$ year on a loan of $12,289.84 \mathrm{Ksh}$. The farmer-borrower in the region will pay on 
average $11,146.40 \mathrm{Ksh}$. As the coverage levels increase to $40 \%$ the mean indemnities increase to 3,527 Ksh on a loan repayment amount of 15,263.62 Ksh, of which the average repayment by the farmer would be 11,735.72 Ksh.

\section{Conclusions and implementation challenges}

In this paper we described the design and rating of risk-contingent credit as was originally developed for a commercially implemented piloted project for mostly poor, resource-limited farmers in Machakos County, Kenya. Machakos (and Sub-Saharan Africa generally) has unique weather related agricultural risks that has limited access to credit. Our approach was to develop a rainfall linked risk-contingent credit that transfers drought risk related perils from borrower to lender via insurance mechanism that provide a balance between business and credit risks for smallholder farmers. We described the methodology used to design and rate the risk-contingent structure using CHIRPS rainfall data from 1981-2016 in Kenya. We illustrated the use of Monte Carlo methods to risk modelling, an approach that can be adapted to many general insurance and credit rating frameworks. Consequently, we opted to prepare this paper in a way that provides practical guidance to practitioners and policy makers, while providing enough depth for agricultural and applied economists to understand the complexities and statistical structures of pricing and bundling insurance and credit together. The methodology can be easily replicated to other areas as similar high quality biophysical data is generally available. The main differences when applying this methodology to other areas is the collection and aggregation of biophysical data on growing seasons with timeframes and agronomic conditions that can vary across geographical areas.

This RCC product has many innovative features: 1) It appears to be the first to develop scientific bundling (bundling itself is not new, we developed scientific bundling technique in financial engineering framework) of rainfall based index insurance and agricultural term loan through actuarially fair pricing, 2) Because the insurance component of RCC substitutes for collateral, it is more financially inclusive than conventional credit products, 3 ) It minimizes the probability of default on loans by producers, improves their risk bearing abilities, and bridges trust in the lender-borrower relationship, 4) The removal of critical liquidity constraints, combined with the inter-temporal transfer of climate risk, an RCC mechanism can achieve better 
targeting of poorer farmers, provide climate resilience, and eliminate climate-based poverty traps, 5) Finally, it also eliminates the drawbacks of standalone index insurance products by not requiring the farmers to pay a premium upfront and out of pocket.

In this paper we design a dual-trigger RCC linked to failures of either long or short rains or both. Our target is grain and cash crop farmers from 11 Sub-Counties in Machakos County of Kenya. It is designed to balance the business and financial risks between borrower and lender when long and or short rains fail. Across all 11 sub-counties we compute an average RCC interest rate of $33.67 \%$. This includes a $25 \%$ load on the actuarially fair premium. To account for unmeasurable risks, we feel that an annual interest rate of $36 \%$ or about $24 \%$ above the base rate of $12 \%$ year would be reasonable. A $36 \%$ annual interest rate is about the same as offered by NGO micro-credit organizations. In addition, many farmers invest in a ROSCA in which they pay $100 \%$ per year. Nonetheless, financial outreach will be required to explain RCC to borrowers. We have conducted games and focus groups in Marsabit and Machakos, as well as dairy regions and all evidence points to a strong interest in RCC. This suggests that the demand for credit is quite inelastic, suggesting that higher interest rates due to a measurable and defined risk premium would not discourage farmers from borrowing at a 3\% per month rate.

Although we designed RCC with the goal of insuring both long and short rains, for a number of practical matters including funding and certain aversions by our local banker and insurer, we only piloted RCC for the long rains in 2017. The details of the pilot will be published separately once data on uptake and impact are evaluated. Notwithstanding the usual challenges that go along with piloting new products in a randomized control trial, the RCC pilot has shown a considerable promise within the smallholder farming communities. The pilot program made approximately $\$ 35,000$ in loans in September 2017 to over 266 farmers who mostly had no previous access to credit. In the RCT, approximately $40 \%$ of farmers accepted a RCC loan whereas about $30 \%$ of farmers took up a traditional credit.

However, there are a range of implementation challenges that are subject to future research and consideration. First, since there might be local variation on rainfall measures and other factors that may lead to different production outcomes, RCC linked to only rainfall may be subject to basis risk. Basis risk has two forms. The first is the spatial risk. As mentioned our election to provide 11 individual district-level contracts, rather than a single meso-level contract for all districts was to minimize spatial disparities in rainfall. However, there is a second type of 
basis risk that may need to be considered and that is the variability of rainfall within a season that could give rise to Type I and Type II error. In the future we will investigate alternative indemnity structures that might better address within season basis risk, rather than a single cumulative measure as we have presented in this paper. Second, our experience from the first round of RCC loan disbursement in Machakos has shown the need for a carefully designed financial education and extension effort to build awareness and to ensure informed decision making by farmers. Insurance bundled credit products are complex and difficult to understand, particularly for populations with low level of literacy. In this regards we developed a participatory pictorial game to communicate RCC to farmers (Shee at al. 2015) which was not only useful for understanding the product but helped in generating demand for the RCC product. This was followed by further instruction at the time RCT choice were made and followed up with an educational program provided by the local bank. 


\section{References}

Alaton, P., Djehiche, B. and Stillberger, D. (2002). “On Modelling and Pricing Weather Derivatives.” Applied Mathematical Finance (9):1-20.

Banerjee, A., Duflo, E., Glennerster, R. and Kinnan, C. (2015). "The miracle of microfinance? Evidence from a randomized evaluation" American Economic Journal: Applied Economics 7(1): $22-53$.

Barrett, C.B., Carter, M. and Little, P. (2006). "Understanding and reducing persistent poverty in Africa: introduction to a special issue" Journal of Development Studies, 42: 167-177

Bester, H. (1985). "Screening vs. Rationing in Credit Markets with Imperfect Information." American Economic Review 75(4): 850-55.

Bewley, J.M., Boehlje, M.D., Gray, A.W., Hogeveen, H., Kenyon, S.J., Eicher, S.D., Schutz, M.M. (2010). "Assessing the potential value for an automated dairy cattle body condition scoring system through stochastic simulation", Agricultural Finance Review, 70(1):126 - 150.

Boucher, S.R., Carter, M.R. and Guirkinger, C. (2008). "Risk rationing and wealth effects in credit markets: theory and implications for agricultural development." American Journal of Agricultural Economics, 90(2), 409-423.

Campbell, S.D. and Diebold, F.X. (2003). "Weather Forecasting for Weather Derivatives" NBER Working Paper 10141, National Bureau of Economic Research, Cambridge MA.

Cao, M. and Wei, J. (2004). "Weather Derivatives Valuation and the Market Price of Weather Risk.” Journal of Futures Markets 24(11):1065-1089.

Carter, M.R. (2011). “The Impact of Interlinked Index Insurance and Credit Contracts on Financial Market Deepening and Small Farm Productivity." Selected Paper. Annual Meeting of the American Applied Economics Association, Pittsburgh PA, July 24-26. 
Casaburi, L. and Wills, J. (2015). "Time vs. state in insurance: experimental evidence from contract farming in Kenya." Working Paper, Stanford University.

Chantarat, S., A. G., Mude, C.B. Barrett, and M.R. Carter, (2013). "Designing index-based livestock insurance for managing asset risk in northern Kenya", Journal of Risk and Insurance, 80(1), 205-237.

Clop-Gallart, M. M. and Juárez-Rubio, F. (2007). "Elicitation of Subjective Crop Yield" Spanish Journal of Agricultural Research, 5(1), 16-24.

Collier, B. A. L. Katchova, J. R. Skees (2011). "Loan portfolio performance and El Niño, an Intervention Analysis", Agricultural Finance Review, 71(1):98 - 119.

Giné, X. and D. Yang (2009). "Insurance, Credit, and Technology Adoption: Field Experimental Evidence from Malawi” Journal of Development Economics 89 (2009) 1-11.

GOK (Government of Kenya) (2014) "KENYA: Situation Analysis for a National Agricultural Insurance Policy (NAIP)"

Johnstone, D.J. and Morduch, J. (2008). "The unbanked: evidence from Indonesia" World Bank Economic Review 22(3): 517-537.

Karlan, D., Kutsoati, E., McMillan, M. and Udry, C. (2011). "Crop Price Indemnified Loans for Farmers: A Pilot Experiment in Rural Ghana.” The Journal of Risk and Insurance, 2011, Vol. 78, No. 1, 37-55.

Malcolm, D.G., Roseboom, J.H., Clark, C.E., and Fazar, W. (1959). “Application of a Technique for Research and Development Program Evaluation”. Operations Research, 7(5): 646-669 
Miranda, M.J. and C. Gonzalez-Vega (2011). "Systemic Risk, Index Insurance, and Optimal Management of Agricultural Loan Portfolios in Developing Countries" American Journal of Agricultural Economics, 93(2): 399-406.

Richards, T.J., Manfredo, M.R. and Sanders, D.R. (2004). "Pricing Weather Derivatives." American Journal of Agricultural Economics, 86(4):1005-1017.

Santos, P. and Barrett, C.B. (2011). "Persistent poverty and informal credit" Journal of Development Economics, 96(2): 337-347.

Shee, A. and Turvey, C. G. (2012). "Collateral-Free Lending with Risk-Contingent Credit for Agricultural Development: Indemnifying Loans against Pulse Crop Price Risk in India." Agricultural Economics, 43: 561-574.

Shee, A., Turvey, C.G. and Woodard, J.D. (2015). "A field study for assessing risk-contingent credit for Kenyan pastoralists and dairy farmers" Agricultural Finance Review, 75(3): 330-348.

Turvey, C. G. (2005). "The pricing of degree-day weather options.” Agricultural Finance Review, 65(1), 59-85.

Turvey, C. G., Gao, X., Nie, R., Wang, L., and Kong, R. (2013). "Subjective risks, objective risks and the crop insurance problem in rural China.” The Geneva Papers on Risk and InsuranceIssues and Practice, 38(3), 612-633. 